\title{
An Experimental and Theoretical Analysis of a Foil-Air Bearing Rotor System
}

DOI:

10.1016/j.jsv.2017.10.036

\section{Document Version}

Accepted author manuscript

Link to publication record in Manchester Research Explorer

\section{Citation for published version (APA):}

Bonello, P., \& Hassan, M. F. B. (2017). An Experimental and Theoretical Analysis of a Foil-Air Bearing Rotor System. Journal of Sound and Vibration, 413, 395-420. https://doi.org/10.1016/j.jsv.2017.10.036

\section{Published in:}

Journal of Sound and Vibration

\section{Citing this paper}

Please note that where the full-text provided on Manchester Research Explorer is the Author Accepted Manuscript or Proof version this may differ from the final Published version. If citing, it is advised that you check and use the publisher's definitive version.

\section{General rights}

Copyright and moral rights for the publications made accessible in the Research Explorer are retained by the authors and/or other copyright owners and it is a condition of accessing publications that users recognise and abide by the legal requirements associated with these rights.

\section{Takedown policy}

If you believe that this document breaches copyright please refer to the University of Manchester's Takedown Procedures [http://man.ac.uk/04Y6Bo] or contact uml.scholarlycommunications@manchester.ac.uk providing relevant details, so we can investigate your claim.

\section{OPEN ACCESS}




\title{
An Experimental and Theoretical Analysis of a Foil-Air Bearing Rotor System
}

\author{
P Bonello ${ }^{1}$, M F Bin Hassan ${ }^{1,2}$ \\ ${ }^{1}$ School of Mechanical, Aerospace and Civil Engineering, University of Manchester, UK, email: \\ philip.bonello@manchester.ac.uk \\ ${ }^{2}$ Faculty of Mechanical Engineering, Universiti Malaysia Pahang, Pekan, Pahang, Malaysia, email: \\ firdaus@ump.edu.my
}

\begin{abstract}
Although there is considerable research on the experimental testing of foil-air bearing (FAB) rotor systems, only a small fraction has been correlated with simulations from a full nonlinear model that links the rotor, air film and foil domains, due to modelling complexity and computational burden. An approach for the simultaneous solution of the three domains as a coupled dynamical system, introduced by the first author and adopted by independent researchers, has recently demonstrated its capability to address this problem. This paper uses this approach, with further developments, in an experimental and theoretical study of a FAB-rotor test rig. The test rig is described in detail, including issues with its commissioning. The theoretical analysis uses a recently introduced modal-based bump foil model that accounts for interaction between the bumps and their inertia. The imposition of pressure constraints on the air film is found to delay the predicted onset of instability speed. The results lend experimental validation to a recent theoretically-based claim that the Gümbel condition may not be appropriate for a practical singlepad FAB. The satisfactory prediction of the salient features of the measured nonlinear behavior shows that the air film is indeed highly influential on the response, in contrast to an earlier finding.
\end{abstract}

Keywords: Foil-air bearings; nonlinear vibration; tribology; rotordynamics 


\section{Nomenclature}

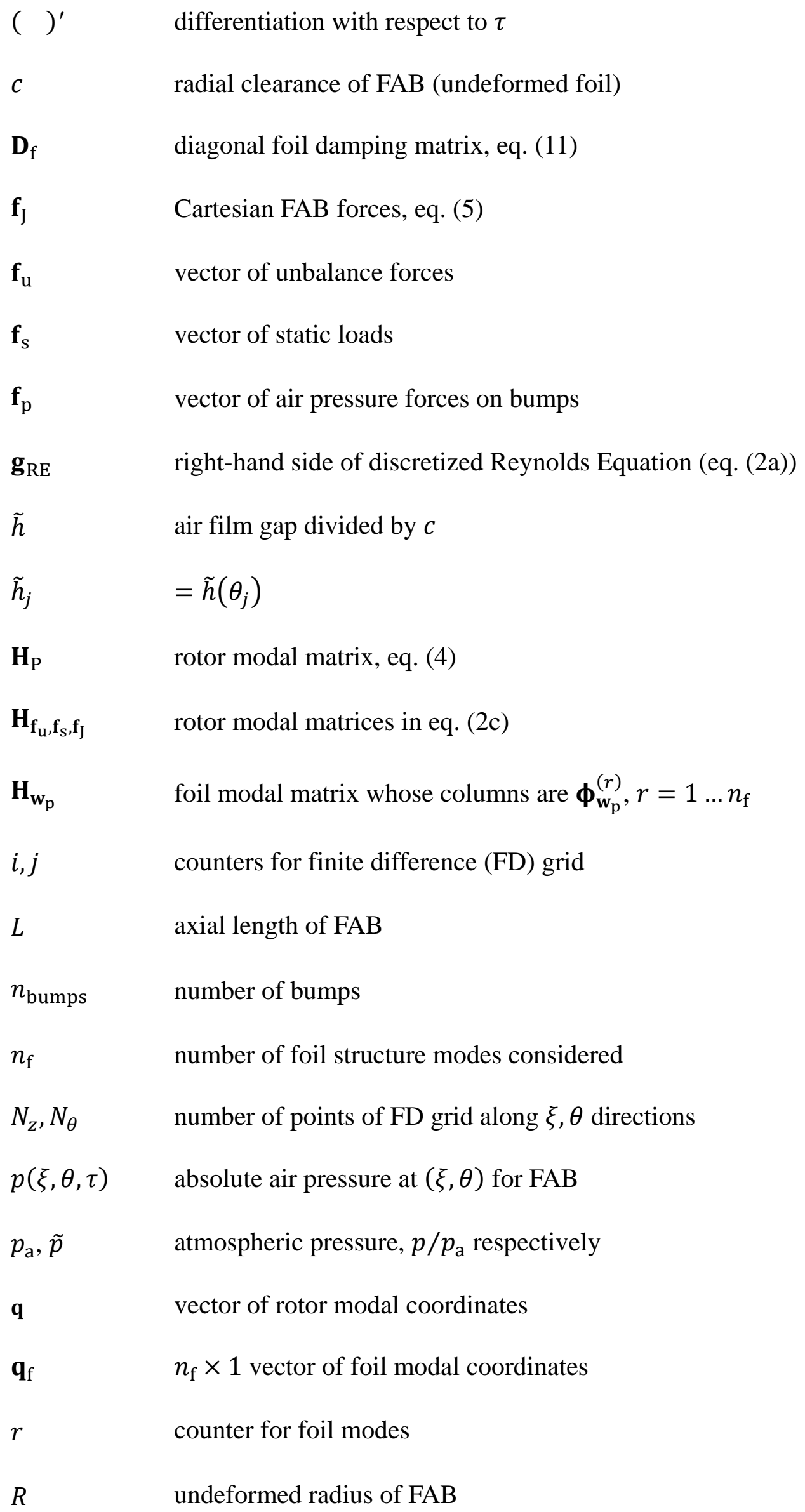


$\mathbf{S}$

$\mathbf{S}_{\mathrm{E}}$

$S$

$t$

$u$

w

$\widetilde{W}$

$\widetilde{w}_{j}$

$\widetilde{\mathbf{w}}$

$\mathbf{W}$

$x, y, z$

$x_{\mathrm{J}}, y_{\mathrm{J}}$

$Z_{\mathrm{f}}$

$\Lambda$

$\Lambda_{\mathrm{f}}$

$\varepsilon$

$\Delta \xi, \Delta \theta \quad$ FD grid spacings in $\xi, \theta$

$\xi$

$\xi_{i}$

$\zeta_{\mathrm{f}_{r}}$

$\theta$

$\theta_{j}$

$\boldsymbol{\phi}_{\mathbf{w}_{\mathrm{p}}}^{(r)}$

$\Lambda$

bump pitch

time in seconds

$=w / c$

$=\widetilde{w}\left(\theta_{j}\right)$

$=\left[\begin{array}{lll}\cdots & \widetilde{w}_{j} & \cdots\end{array}\right]^{\mathrm{T}}$

$=\left[x_{\mathrm{J}} / c \quad y_{\mathrm{J}} / c\right]$

$\xi, i=1, \ldots, N_{z}$

$\theta, j=1, \ldots, N_{\theta}$

bearing number $[5,6]$ vector of state variables (eq. (1))

static equilibrium value of $\mathbf{s}$

foil deflection in tangential direction

foil deflection in radial direction

$n_{\text {bumps }} \times 1$ vector containing the radial displacements at the bump apexes

Cartesian coordinate system

Cartesian displacements of journal centre J relative to (fixed) bearing centre

local axial coordinate for FAB

diagonal matrix of squares of rotor natural circular frequencies

diagonal matrix of squares of foil natural circular frequencies

$=z_{\mathrm{f}} / R$

viscous damping ratio of foil mode no. $r$

angular local bearing coordinate (Figure 1)

$n_{\text {bumps }} \times 1$ mass-normalised eigenvector in mode no. $r$ containing the radial

displacements at the apexes of the bumps 


$$
\begin{array}{ll}
\psi(\xi, \theta, \tau) & =\tilde{p} \tilde{h} \\
\psi_{i, j}(\tau) & =\psi\left(\xi_{i}, \theta_{j}, \tau\right) \\
\Psi & =\left[\begin{array}{lll}
\cdots & \psi_{i, j}(\tau) & \cdots
\end{array}\right]^{\mathrm{T}} \\
\tau & \text { non-dimensional time }(=\Omega t / 2) \\
\Omega & \text { rotational speed in rad/s } \\
\lambda_{\mathrm{L}} & \text { leading eigenvalue of state Jacobian } \\
\omega_{\mathrm{f}_{r}} & \text { natural circular frequency of foil mode no. } r \text { in rad/s } \\
\chi & \text { nonlinear vector function of } \mathrm{s} \text { in eq. (1) }
\end{array}
$$

\section{INTRODUCTION}

The foil air bearing (FAB) is a key enabler of oil-free turbomachinery technology and its environmental and technological benefits are well documented [1]. Breakthroughs in materials and manufacturing technology reported in the late 1990s/early 2000s have intensified research into its applicability to an ever increasing range of turbomachinery [2]. However, the analysis of FAB-rotor systems presents a challenging nonlinear problem that discourages their use [3]. As stated by Balducchi et al. [3], the designer is not only faced with a bearing that is considerably more complex than traditional journal bearings, but experimental results show nonlinear phenomena that cannot be predicted with traditional theoretical models based on linear rotordynamic coefficients.

The dynamics of FAB-rotor systems are governed by the nonlinear interaction between the air film, foil structure and rotor domains, where each domain is governed by time-based differential equations [4-6]. As discussed in [4-6], in order to reduce the computational burden, the problem has been subjected to simplification to one or more aspects. One major simplification has been the practice to decouple the air film, foil and rotor equations e.g. as done in [7-9]. This was done by approximating the air film equations as algebraic, rather than differential, equations. As explained in [4-6] and [10, 11], the solution technique 
used in [7-9] was therefore a non-simultaneous approach that involved "time lagging” between the air film equations and those of the foil and rotor.

A significant advance in the research into FAB-rotor solution techniques was made in 2013/14 by researchers at the University of Manchester (Bonello and Pham) [12, 5, 6], who expressed the FAB-rotor system in the generic format of a coupled system of time-based differential equations:

$$
\mathbf{s}^{\prime}=\chi(\tau, \mathbf{s})
$$

where ( $)^{\prime}$ denotes differentiation with respect to the time variable $\tau, \mathbf{s}$ is the state vector, containing the state variables from all three domains (air film, foil and rotor), and $\boldsymbol{\chi}$ is a vector of nonlinear functions of $\tau$ and s. Bonello and Pham $[12,5,6]$ then proceeded to develop simultaneous solution methods for this system that were computationally efficient. The state-space format of eq. (1) is the proper generic format of a nonlinear dynamical system (e.g. see Ott [13]). It not only preserves the true simultaneous coupling between the three domains, but enables the use of readily available advanced integrator routines, for the transient nonlinear dynamic analysis (TNDA), that were devised for this universal format [14]. It also enables a reliable method for the analysis of stability of the static equilibrium condition that is based on the direct linearisation of eq. (1). Such a linear stability method, referred to as static equilibrium stability analysis (SESA) in [6], is based on an eigenvalue analysis of the Jacobian matrix of the right hand side of eq. (1) and its result for the onset of instability (OIS) speed is therefore fully consistent with that obtained via TNDA of the full nonlinear system $[5,6]$. This contrasts with the traditional linear stability method based on Lund's perturbation approach (i.e. deriving stiffness and damping coefficients) [15, 7, 9] which has recently been shown by Larsen et al. [16] to yield erroneous results when applied to bearings with flexible foil structures and a certain level of loading.

The impact of the simultaneous solution approach $[12,5,6]$ is evident from the fact that its basic strategy has recently been taken up by other researchers based in the Technical University of Denmark (DTU), (Santos and co-researchers) [10, 11, 16-19], after assessing the issues with the non-simultaneous solution 
approach. Using this new approach, the DTU researchers obtained good correlation with results from an experimental rig [11].

The works by Bonello et al. [4-6, 12] have involved the FAB with a single $360^{\circ}$ pad shown in Figure 1 , whereas those by Larsen et al. (DTU) $[10,11,16]$ have involved a FAB with three pads equally spaced circumferentially. Both works neglected the top foil and the individual bumps of the foil were modelled as independent spring-damper subsystems, also referred to as simple elastic foundation model (SEFM). In their code, Larsen et al. $[10,11,16]$ impose a lower limit to the air film pressure, when integrating for the bearing forces. This condition, which they refer to as the Gümbel condition, is a retrospective correction for the detachment of the top foil from the bump foil in regions of sub-atmospheric pressure, where it is assumed that the top foil deflects to a position where the pressure on either side is equalised at atmospheric pressure [11]. In a most recent work from DTU (Nielsen and Santos [17]) a model that allowed for the separation of the top foil from the bump foil was proposed. It was based on a modal model of the top foil, thus including both its flexibility and inertia. The bump foil was still modelled using the SEFM but its stiffness was only effective when it was in contact with the top foil, resulting in a bilinear model. This model was correlated in [17] against theoretical results from the previous code (that applied the Gümbel condition). The test case used in [17] was a single $360^{\circ}$ pad with clamped leading edge and free trailing edge (CLE/FTE). This is opposite to the way single-pad FABs are typically used in practice, wherein the recommended operating mode is a free leading edge and a clamped trailing edge (FLE/CTE), as shown in Figure 1. The manufacturer's operating instructions of the FAB used in the experimental work of the present paper state that reversing the rotation from that shown in Figure 1 (thus changing the mode from FLE/CTE to CLE/FTE) may result in premature failure. This is consistent with the statement by Larsen [18] that single-pad FABs are always used in FLE/CTE mode to prevent the pad being ripped off by capstan/Eyetelwein winch forces (Larsen [18] goes on to say that multi-pad FABs can take both operating modes, allowing the journal to be safely rotated either way). The reason for using the atypical CLE/FTE configuration for the single-pad FAB in [17] is found in the associated PhD thesis [19], where it was found that the bilinear model of [17] produced similar results to the SEFM-Gümbel 
model in the CLE/FTE case but not the FLE/CTE case. In the latter case, the bilinear model revealed sub-atmospheric pressures since (for the case considered, involving static loading only) these formed towards the trailing edge where the foil cannot freely separate (see Figure 1). This theoretical finding is significant since the Gümbel condition has been commonly used in theoretical works involving singlepad FABs (e.g. $[9,17,20]$ ) despite the fact that FLE/CTE is the typical operating mode for such FABs. On the other hand, the previous works by Bonello et al $[4-6,12]$ on single-pad FABs did not impose the Gümbel condition. It should be emphasized that the use of the Gümbel condition by Larsen et al. in their works $[10,11,16]$ is perfectly justified for the three-pad FAB used there, since this configuration used clamped leading edges and free trailing edges for each pad.

The aforementioned work by Larsen and Santos [11] is one of very few works that correlated experimental results with predictions from a full nonlinear model that links the rotor, air film and foil domains. For example, Heshmat [21, 22] performed valuable pioneering work on high speed FAB-rotor test rigs and Choe et al. investigated FAB use on complex configurations (two coupled FAB-rotor systems) [23]. However, in either case, the experimental results were correlated with predictions based on linear rotordynamic analysis. San Andres et al. [24] and Balducchi et al. [3] correlated their experimental results with the predictions from a nonlinear model that omitted the air film and replaced the FAB by a nonlinear stiffness spring identified from static loading experiments on the foil. The assumption that the air film has infinite stiffness (and can therefore be ignored) is supposed to be theoretically justified for very high speeds [3], but very limited agreement with experiment was reported in [3], despite reaching speeds of up to $97 \mathrm{krpm}$.

The aim of this paper is to present an experimental and theoretical analysis of a rotor-FAB test rig. As in the work by Larsen and Santos [11], the theoretical model involves the full nonlinear model that simultaneously couples the rotor, air film and foil domains (eq. (1)). However, in contrast to [11]: 
- A full foil structure modal model (FFSMM) is used for the bump foil, instead of the SEFM. This model allows for dynamic interaction between the bumps and their inertia. It was recently introduced by the authors in [4], where it was validated against experimental and theoretical results in the literature for the case of static equilibrium rotational conditions.

- The FAB used is a single $360^{\circ}$ pad with free leading edge (Figure 1), and a variety of boundary conditions for the air film are investigated. The applicability of the Gümbel condition is examined, in the light of the theoretical finding by Nielsen [19].

- Self-excitation (instability) is predicted within the operating speed range of the test rig (which is of different design from [11]) and the dynamics are investigated using both TNDA and SESA. Moreover, the nonlinear phenomena measured and predicted (with the air film as the only source of nonlinearity) will be revealed to be strikingly similar to those observed on the rig of San Andres and Kim [24], who discounted both self-excitation and the air film in their analysis.

Section 2 describes the test rig. Section 3 presents the theoretical model. Section 4 presents and discusses the theoretical and experimental results.

\section{Figure 1 here}

\section{TEST RIG DESCRIPTION}

With reference to Figure 2, the test rotor is composed of a solid steel shaft of length $0.454 \mathrm{~m}$ supported by a self-aligning ball bearing arrangement at the left-hand end and a FAB at the other end. The housings of the bearings are bolted to a cast iron bedplate that rests on a concrete block mounted via isolators. The self-aligning bearing is a tandem arrangement of two super-precision ball bearings that use oil-air lubrication for high-speed operation. The first generation bump-type FAB (Figure 1) has the geometric dimensions specified in [4] (Table 1) and was manufactured by Mechanical Solutions, Inc. The bearing was installed so that the leading/trailing edges were located at the uppermost position. Chrome plating 
was applied to the FAB journal in order to minimize the friction between the shaft and the top foil during start-up i.e. the initial rubbing before the speed is sufficiently high for the hydrodynamic air film to form between the journal and the compliant foil boundary. The average diameter of the undeformed top foil of the FAB (denoted by $D_{\mathrm{FAB}}$ ) was 1.5013 inch. This was calculated by the bearing manufacturer from measurements of the diametral clearance using a method similar to that of Ruscitto et al. [25], wherein a radial load was applied to the bearing and its movement relative to a dummy journal was measured using a dial indicator. The average diameter of the undeformed top foil of the FAB was then specified as $D_{\mathrm{FAB}}=D_{\text {dummy }}+2 \bar{c}_{\beta}$ where $D_{\text {dummy }}$ is the diameter of the dummy journal and $\bar{c}_{\beta}$ is the average of the radial clearances measured at different angular positions $\beta$. Knowing the value of $D_{\mathrm{FAB}}$, the journal of the test rig was precision machined to give a nominal radial clearance of $33.75 \mu \mathrm{m}$, which is very close to the value of $32 \mu \mathrm{m}$ often quoted for a bearing of these dimensions [7, 8, 25].

\section{Figure 2 here}

\begin{tabular}{|c|c|c|c|c|c|}
\hline \multicolumn{4}{|c|}{ Foil } & \multicolumn{2}{|c|}{ Air film } \\
\hline no. of bumps & 26 & width (mm) & 38.1 & radius $R(\mathrm{~mm})$ & 19.05 \\
\hline $\begin{array}{l}\text { bump length } \\
\text { (mm) }\end{array}$ & 3.209 & foil thickness (mm) & 0.102 & length $L(\mathrm{~mm})$ & 38.1 \\
\hline bump pitch (mm) & 4.572 & $\begin{array}{l}\text { Young Modulus } \\
\left(\mathrm{GN} / \mathrm{m}^{2}\right)\end{array}$ & 214 & $\begin{array}{l}\text { radial clearance } c \\
(\mu \mathrm{m})\end{array}$ & 33.75 \\
\hline $\begin{array}{l}\text { bump height } \\
\text { (mm) }\end{array}$ & 0.5 & density $\left(\mathrm{kg} / \mathrm{m}^{3}\right)$ & 8280 & $\begin{array}{l}\text { air viscosity } \mu \\
\left(\times 10^{-5} \mathrm{Ns} / \mathrm{m}^{2}\right)\end{array}$ & 1.95 \\
\hline
\end{tabular}

Table 1. Foil air bearing specifications.

The rotor was driven by an air motor which has a starting torque $0.45 \mathrm{Nm}$ and no-load maximum speed 45,000 rpm and 300W power at the maximum air pressure 6.3 bar. During start up, to overcome the friction torque, the air motor may need to be assisted by an auxiliary electric motor (12 V dc). This idea 
was borrowed from the rig of San Andres and co-workers [24, 26]. In the present case, a pneumaticallycontrolled mechanism was designed to engage/disengage the auxiliary motor. When engaged, the combined torque from the auxiliary motor and the air motor was enough to overcome the starting (friction) torque in the FAB. Once the shaft speed is sufficiently high, the FAB journal rides on air, the rubbing friction disappears in principle, and the auxiliary electric motor can be disengaged, enabling the air motor to drive the shaft by itself and accelerate it to higher speed.

\subsection{Commissioning Issues}

As originally designed, the shaft had a mass of $3.0 \mathrm{~kg}$. However, the static loading was considered one of two reasons (the other being misalignment) for excessive start-up friction that prevented acceleration to a sufficiently high speed for an adequate hydrodynamic air film to form, and thus preventing subsequent ("friction-free”) acceleration to the desired top speed. Hence, the shaft and its integral disk were machined down to a mass of $2.0 \mathrm{~kg}$.

With reference to Figure 3, the air motor and the driven shaft were connected by a cylindrical plastic coupling. The use of this coupling meant that the left-hand end of the driven rotor was not exactly pivoted since this coupling would exert a bending moment. However, experimental testing showed that this limitation was not critically significant.

\section{Figure 3 here}

Correct alignment of the shaft was found to be a critical issue in reducing the rubbing. Misalignment results in the FAB journal centerline being oblique relative to the centerline of the bearing shell in the rest condition. This means that the journal may get stuck at the edges of the top foil as it is being turned. Moreover, in this condition, the bending moment from the coupling will increase the tilt, and hence the rubbing at the foil edges, as the shaft is turned. Hence, each time the FAB was installed, the shaft was 
aligned by adding shims underneath the left hand or right hand outer housings $\mathrm{B}$, depending on the dial reading at position (2) relative to (1) (Figure 3).

The above-described measures considerably reduced the friction torque, raising the achievable top speed from less than 10,000 rpm to 28,000 rpm. Moreover, after numerous start-ups with a given FAB, it was found that the required starting torque became smaller due to wear at the bearing edges. Hence, the auxiliary electric motor was no longer needed to start up the test rig after a few months of regular use.

Since the simulations revealed strong sub-synchronous vibration (confirmed by experiment), the test rig was not balanced with the FAB in place. Instead, for balancing purposes, the FAB (Figure 3) was removed and the shaft supported by another self-aligning ball bearing at a location to the right of the disc. The pedestals of the two ball bearings were flexibly mounted and the shaft balanced to grade G2.5 according to ISO Standard 1940 [27]. After balancing, the configuration in Figure 3 was restored, with the housings of both bearings rigidly fixed to the bedplate as shown.

\subsection{Preliminary experiments and simulations on linear part}

In the nonlinear rotordynamic analysis (section 3), the nonlinear FAB forces, the rotational unbalance forces (at the disc), and the distributed gyroscopic effect and static (gravity) loading, are regarded as external excitations acting on the remaining part of the system, which can be referred to as the "linear part”. Hence, the physical coordinates at a general point $\mathrm{P}$ along the rotor can be transformed to modal coordinates using a truncated series of undamped free vibration modes of the linear part, in accordance with the approach introduced in [6] for FAB-rotor systems, that follows the Adams approach for rotor systems with generic nonlinear bearings [28]. This linear part is therefore defined as the system without the FAB in place. In the theoretical model, the linear part was taken to be the rotor pinned at the selfaligning bearing at $\mathrm{O}$ (assumed to be a pivot of infinite stiffness - see Figure 3) and free elsewhere (in reality, there would be the additional constraint from the plastic coupling). The eigenmodes of the linear part were modeled using finite element analysis (Timoshenko beam elements) and the geometric and 
physical properties of the rotor are given in Appendix A. To validate this, an impact test on the shaft was performed, with the coupling in place and the FAB replaced by a soft foam support (Figure 4(a)). Figure 4(b) compares the receptance FRFs obtained from the impact test and FE analysis. The discrepancies are attributed to the measured resonance at $24 \mathrm{~Hz}$, which is not present in the theoretical FRFs. This is expected since the theoretical linear part was pinned-free, which means that the first theoretical mode is at $0 \mathrm{~Hz}$. On the other hand, the actual linear part was constrained by the soft foam support at the FAB location and the coupling between the motor and the shaft. Both these effects contributed towards increasing the frequency of the first mode to $24 \mathrm{~Hz}$. Given that the minimum speed of the rig is 2000 rpm, the omission of the coupling stiffness is not expected to affect the predictions. The second mode is also not significantly affected by these additional constraints. In fact, its predicted and measured frequencies were found to be 489 and $479 \mathrm{~Hz}$ respectively, showing $2 \%$ difference.

\section{Figure 4 here}

Figure 5 shows the mass-normalised mode shapes used for each of the $x z$ and $y z$ planes in the nonlinear analysis (section 3). The machining of the shaft (as mentioned in the third paragraph of section 2), had the undesired effect of not only reducing the first calculated bending mode of the linear part to $479 \mathrm{~Hz}$, but shifting its node to a location that was just one $1 \mathrm{~mm}$ away from the mid-section of the FAB. For this

reason, the simulations were limited to 29,000 rpm (483 Hz) (as explained in Section 4.1) and the experiments were limited to 28,000 rpm (as explained in Section 4.2).

\section{Figure 5 here}

\section{THEORETICAL MODELLING}

The differential equations governing the nonlinear dynamics of the rotor-FAB system can be expressed in the form of eq. (1) as follows: 


$$
\begin{aligned}
& \boldsymbol{\psi}^{\prime}=\mathbf{g}_{\mathrm{RE}}\left(\boldsymbol{\psi}, \widetilde{\mathbf{w}}\left(\mathbf{q}_{\mathrm{f}}\right), \boldsymbol{\varepsilon}(\mathbf{q})\right) \\
& {\left[\begin{array}{c}
\mathbf{q}_{\mathrm{f}} \\
\mathbf{q}_{\mathrm{f}}^{\prime}
\end{array}\right]^{\prime}=\left[\begin{array}{c}
\mathbf{q}_{\mathrm{f}}^{\prime} \\
\left.\frac{4}{\Omega^{2}}\left[-(\Omega / 2) \mathbf{D}_{\mathrm{f}} \mathbf{q}_{\mathrm{f}}^{\prime}-\boldsymbol{\Lambda}_{\mathrm{f}} \mathbf{q}_{\mathrm{f}}+\mathbf{H}_{\mathbf{w}_{\mathrm{p}}}^{\mathbf{T}} \mathbf{f}_{\mathrm{p}}\left(\boldsymbol{\Psi}, \mathbf{q}_{\mathrm{f}}, \boldsymbol{\varepsilon}(\mathbf{q})\right)\right]\right]
\end{array}\right]} \\
& {\left[\begin{array}{c}
\mathbf{q}_{\mathbf{q}^{\prime}}^{\prime}
\end{array}\right]^{\prime}=\left[\begin{array}{c}
\mathbf{q}^{\prime} \\
\frac{4}{\Omega^{2}}\left[-\boldsymbol{\Lambda} \mathbf{q}+\mathbf{H}_{\mathbf{f}_{\mathrm{u}}}^{\mathrm{T}} \mathbf{f}_{\mathrm{u}}(\tau)+\mathbf{H}_{\mathbf{f}_{\mathrm{s}}}^{\mathrm{T}} \mathbf{f}_{\mathrm{s}}+(\Omega / 2) \mathbf{H}_{\mathbf{g}}^{\mathrm{T}} \mathbf{P} \mathbf{H}_{\boldsymbol{\alpha}} \mathbf{q}^{\prime}+\mathbf{H}_{\mathbf{f}_{\mathrm{J}}}^{\mathrm{T}} \mathbf{f}_{\mathrm{J}}\left(\boldsymbol{\Psi}, \mathbf{q}_{\mathrm{f}}, \boldsymbol{\varepsilon}(\mathbf{q})\right)\right]
\end{array}\right]}
\end{aligned}
$$

where the non-dimensional time is defined as $\tau=\Omega t / 2$ ( $\Omega$ being the rotational speed) and the vector state variable $\mathbf{s}$ comprises sub-vectors containing state variables relating to the air film $(\boldsymbol{\Psi})$, the bump foil $\left(\mathbf{q}_{\mathrm{f}}, \mathbf{q}_{\mathrm{f}}^{\prime}\right)$ and the rotor $\left(\mathbf{q}, \mathbf{q}^{\prime}\right)$ :

$$
\mathbf{s}=\left[\begin{array}{c}
\mathbf{\Psi} \\
\mathbf{q}_{\mathrm{f}} \\
\mathbf{q}_{\mathrm{f}} \\
\mathbf{q} \\
\mathbf{q}^{\prime}
\end{array}\right]
$$

The details of these three equation sets (2a), (b), (2c), pertaining to the air film, foil structure and rotor domains respectively, are described in turn in the following three sub-sections, starting with eqs. (2c).

\subsection{Rotor Equations (eqs. (2c))}

The modal transformation uses 4 modes of the linear part at zero rotational speed. These comprise 2 rigid body modes $(0 \mathrm{~Hz})$ in the $x z, y z$ planes respectively and 2 bending modes $(479 \mathrm{~Hz})$ in the $x z, y z$ planes respectively (Figure 5). $\mathbf{q}$ is the $4 \times 1$ column matrix (vector) of modal coordinates and $\boldsymbol{\Lambda}$ the diagonal matrix of the squares of the natural frequencies of the 4 modes. The Cartesian coordinates of any point $\mathrm{P}$ along the rotor are given by:

$$
\left[\begin{array}{ll}
x_{\mathrm{P}} & y_{\mathrm{P}}
\end{array}\right]^{\mathrm{T}}=\mathbf{H}_{\mathrm{P}} \mathbf{q}(\tau)=\left[\begin{array}{lll}
\boldsymbol{\varphi}_{\mathrm{P}}^{(1)} & \cdots & \boldsymbol{\varphi}_{\mathrm{P}}^{(4)}
\end{array}\right] \mathbf{q}(\tau)
$$

where the columns of the modal matrix $\mathbf{H}_{\mathrm{P}}$ are the mass-normalised eigenvectors of the respective modes containing the modal displacements evaluated at the degrees of freedom in $\left[\begin{array}{ll}x_{\mathrm{P}} & y_{\mathrm{P}}\end{array}\right]^{\mathrm{T}}$.

$\mathbf{f}_{\mathrm{u}}$ the $2 \times 1$ vector of rotational unbalance forces at the disc in the $x, y$ directions, and $\mathbf{f}_{\mathrm{s}}$ the vector of the distributed weight of the rotor. Since the rotor is statically determinate, $\mathbf{f}_{\mathrm{s}}$ comprises a single element 
$(-13.9 \mathrm{~N})$, the equivalent static load at the FAB journal. The term $\mathbf{H}_{\mathbf{g}}^{\mathrm{T}} \mathbf{P} \mathbf{H}_{\boldsymbol{\alpha}} \dot{\mathbf{q}}$, defined in [29], accounts for the gyroscopic effect which is assumed to be concentrated at a number of locations that are distributed along the rotor. The gyroscopic effect is regarded as an externally applied moment on the rotor, enabling the advantageous use of speed-independent modes (taken at zero speed) in the transformation [28]. $\mathbf{H}_{\mathbf{f}_{\mathrm{u}}, \mathbf{f}_{\mathrm{s}}, \mathbf{f}_{\mathrm{j}}}$ in the forcing terms are modal matrices whose 4 columns are the mass-normalised eigenvectors describing the motions of the linear part at the degrees of freedom of the corresponding excitations. $\mathbf{f}_{\mathrm{J}}$ is the $2 \times 1$ vector of air film pressure forces exerted by the FAB on its journal in the $x, y$ directions, obtained by integrating the air film pressure distribution $p(\xi, \theta, \tau)$ over the bearing area:

$$
\mathbf{f}_{\mathrm{J}}=-2 R^{2} \int_{\xi=0}^{0.5 L / R} \int_{\theta=0}^{2 \pi}\left(p-p_{\mathrm{a}}\right)\left[\begin{array}{c}
\cos \theta \\
\sin \theta
\end{array}\right] \mathrm{d} \theta d \xi
$$

where $R$ and $L$ are the radius and length respectively of the FAB, $\xi=\frac{z_{\mathrm{f}}}{R}$ the non-dimensional axial coordinate. As seen from eq. (2c), $\mathbf{f}_{\mathrm{J}}$ can be calculated for known air film state variables in $\Psi$, known modal co-ordinates of the foil $\mathbf{q}_{\mathrm{f}}$, and known journal eccentricity vector

$$
\boldsymbol{\varepsilon}=\left[x_{\mathrm{J}} / c \quad y_{\mathrm{J}} / c\right]=\mathbf{H}_{\mathbf{f}_{\mathrm{J}}} \mathbf{q}(\tau) / c
$$

\subsection{Foil Equations (eqs. (2b))}

The thickness of the air film is dependent on both $\boldsymbol{\varepsilon}$ and the radial deformation $w$ of the clearance boundary. In the present case the full foil structure modal model (FFSMM) of the bump foil [4], is used to determine $w$. It is based on the principle that the vibrating shape of the bump foil can be represented by a truncated series of $n_{\mathrm{f}}$ undamped modes. The dynamics are then represented by eq. (2b), where $\mathbf{q}_{\mathrm{f}}$ is the $n_{\mathrm{f}} \times 1$ vector of modal coordinates and $\boldsymbol{\Lambda}_{\mathrm{f}}$ is the diagonal matrix

$$
\boldsymbol{\Lambda}_{\mathrm{f}}=\operatorname{diag}\left[\begin{array}{lll}
\cdots & \omega_{\mathrm{f}_{r}}^{2} & \cdots
\end{array}\right]
$$

where $\omega_{\mathrm{f}_{r}}$ is the undamped natural frequency ( $\left.\mathrm{rad} / \mathrm{s}\right)$ of mode no. $r . \mathbf{H}_{\mathbf{w}_{\mathrm{p}}}$ is the modal matrix whose columns are the $n_{\text {bumps }} \times 1$ mass-normalised eigenvectors containing the radial displacements at the apexes of the bumps in each of the $n_{\mathrm{f}}$ modes (as per cylindrical coordinate system in Figure 1 ): 


$$
\mathbf{H}_{\mathbf{w}_{\mathrm{p}}}=\left[\begin{array}{lll}
\boldsymbol{\phi}_{\mathbf{w}_{\mathrm{p}}}^{(1)} & \cdots & \boldsymbol{\phi}_{\mathbf{w}_{\mathrm{p}}}^{\left(n_{\mathrm{f}}\right)}
\end{array}\right]
$$

$\mathbf{f}_{\mathrm{p}}$ is the $n_{\text {bumps }} \times 1$ vector of air pressure forces on the bumps that, for known $\left(\boldsymbol{\Psi}, \mathbf{q}_{\mathrm{f}}, \boldsymbol{\varepsilon}\right)$, can be obtained by integrating $p(\xi, \theta, \tau)$ over a bump projected area of $S \times L$, where $S$ is the pitch:

$$
\mathbf{f}_{\mathrm{p}}=\left[\begin{array}{lll}
\cdots & f_{k} & \cdots
\end{array}\right]^{\mathrm{T}}, \quad f_{k}=-2 R^{2} \int_{\xi=0}^{0.5 L / R} \int_{\theta=\theta_{k}-S / R}^{\theta_{k}+S / R}\left(p-p_{\mathrm{a}}\right) \mathrm{d} \theta d \xi
$$

For known $\mathbf{q}_{\mathrm{f}}$ the $n_{\text {bumps }} \times 1$ vector of radial displacements $\mathbf{w}_{\mathrm{p}}$ at the apexes can be obtained directly from the eigenvectors containing the radial displacements:

$$
\mathbf{w}_{\mathrm{p}}=\mathbf{H}_{\mathbf{w}_{\mathrm{p}}} \mathbf{q}_{\mathrm{f}}(\tau)
$$

As discussed in [4], $\mathbf{w}_{\mathrm{p}}$ can alternatively be obtained indirectly from the eigenvectors containing the tangential displacements at the apexes of the bumps, which may offer better convergence.

The assumptions of the FFSMM are listed below (reference is made to the authors' previous paper [4], where they are discussed in greater detail):

a) The stiffness and inertia of the top foil are neglected and it is assumed to be in contact with the bump at all times for the purpose of determining the local radial deflection $w$ of the top foil.

b) The variation of the top foil deflection in the axial $\left(z_{\mathrm{f}}\right)$ direction is assumed to be negligible, meaning that $w$ is a function of $\theta$ only.

c) For given $\theta$, the top foil deflection $w$ is obtained by interpolation from the $n_{\text {bumps }} \times 1$ vector $\mathbf{w}_{\mathbf{p}}$ given by equation (10). This effectively assumes that the sagging of the top foil between the apexes is neglected.

d) The damping effect of the nonlinear friction forces (bump foil/bearing shell and bump foil/top foil) is approximated as an equivalent viscous damping effect via the damping matrix $\mathbf{D}_{\mathrm{f}}$, where $\zeta_{\mathrm{f}_{r}}$ is the viscous damping ratio of mode no. $r$.

$$
\mathbf{D}_{\mathrm{f}}=\operatorname{diag}\left[\begin{array}{lll}
\cdots & 2 \zeta_{\mathrm{f}_{r}} \omega_{\mathrm{f}_{r}} & \cdots
\end{array}\right]
$$


Assumptions (a-c) are made in many previous works e.g. [7, 8, 11]. Assumption (d) is analogous to the equivalent viscous damping used in the case of spring-damper foil models e.g. [3, 5, 7, 11, 17, 24] which was based on a hysteretic damping loss factor and an assumed frequency (typically taken to be the rotational speed).

The modal analysis of the bump foil in isolation was experimentally validated by the authors in [4] where the authors also validated the rotor-FAB model of eq. (2a-c) against published experimental results for the case of static equilibrium rotational conditions. The eigenvalues $\omega_{\mathrm{f}_{r}}^{2}$ and eigenvectors $\boldsymbol{\phi}_{\mathbf{w}_{\mathrm{p}}}^{(r)}$ are calculated as in [4] by FE in two dimensions (2D), using beam elements for the bumps (cross-verified in [4] against 3D-FE results using solid elements). The FE analysis used the cylindrical coordinate system (Figure 1) i.e. accounted for the curvature of the bearing shell. The geometry of the bump foil is identical to [4] but the Young's Modulus and density are slightly different (Table 1). The mode-shapes are virtually identical to those presented in Figure 5 of reference [4] and the natural frequencies of the first five modes in the present case are (in kHz): 2.243, 6.669, 10.916, 14.888, 18.518.

In eqs (2b). $n_{\mathrm{f}}=5$ modes were used since this gave good convergence of the physical displacements [4]. The viscous damping ratio $\zeta_{\mathrm{f}_{r}}$ used for all modes was 0.125 , which is equivalent to a hysteretic damping loss factor value of 0.25 [4], that is typically used for the standard FAB used here [7]. This relatively high value of loss factor/damping ratio accounts for the fact that it is being used as a substitute for the Coulomb friction effect [11]. The FFSMM holds the prospect of using actual nonlinear friction forces but this requires further work [4]. In fact, DTU researchers have just started investigating the inclusion of Coulomb friction forces into the simultaneous solution approach (eq. (1)) but have so far reported unsatisfactory predictions for the unbalance response [30], in contrast to their previous results based on the equivalent linear damping approach [11].

\subsection{Air Film Equations (eqs. (2a))}


Eqs (2a) comprise the discretised form of the isothermal Reynolds Equation (RE) of the air film, which governs the pressure function $p(\xi, \theta, \tau)$ :

$$
\psi^{\prime}=\frac{1}{\Lambda}\left\{\frac{\partial}{\partial \theta}\left[\psi\left(\tilde{h} \frac{\partial \psi}{\partial \theta}-\psi \frac{\partial \widetilde{h}}{\partial \theta}\right)\right]+\frac{\partial}{\partial \xi}\left[\psi\left(\tilde{h} \frac{\partial \psi}{\partial \xi}-\psi \frac{\partial \widetilde{h}}{\partial \xi}\right)\right]\right\}-\frac{\partial \psi}{\partial \theta}
$$

The RE is formulated in terms of the combined state variable $\psi \equiv \tilde{p} \tilde{h}$ where $\tilde{p}=\frac{p}{p_{\mathrm{a}}}$ and $\tilde{h}=\frac{h}{c}$ are the non-dimensional air film pressure and thickness at a position $(\xi, \theta)$ (where $p_{\mathrm{a}}$ is the absolute atmospheric pressure and $c$ the nominal radial clearance). The variable $\psi$ was introduced into FAB work by Bonello and Pham [12, 5] and has since been adopted by others [10, 11, 16, 17-19] who have followed a similar simultaneous solution strategy. In eq. (12), $\Lambda$ is the bearing number [5] and the non-dimensional air film gap is given by:

$$
\tilde{h}(\theta)=1-\boldsymbol{\varepsilon}^{\mathrm{T}}\left[\begin{array}{c}
\cos \theta \\
\sin \theta
\end{array}\right]+\widetilde{w}(\theta)
$$

where $\widetilde{w}=w / c$ is the non-dimensional top foil deflection in the radial direction at angular position $\theta$.

The RE is discretised over a finite difference (FD) grid [12]. Since the bearing is open at both ends, symmetry can be exploited and the FD grid need only cover half the axial length of the bearing. The rectangular grid has $N_{z} \times N_{\theta}$ points where $\xi=\xi_{i}, i=1, \ldots, N_{z}, \theta=\theta_{j}, j=1, \ldots, N_{\theta}$. The location $\xi=\xi_{N_{z}}$ corresponds to the middle cross-section of the bearing (i.e. $\xi_{N_{z}}=0.5 L / R$ ). The location $\xi=\xi_{1}$ corresponds to the cross-section that is displaced inwards from the bearing edge by a distance $\Delta \xi$ i.e. $\xi_{1}=\Delta \xi$, and the bearing edge, where $\psi=\tilde{h}$ (i.e. $\tilde{p}=1$ ), is excluded from the FD grid. The pad covers the full extent in the $\theta$ direction (Figure 1) i.e. from $\theta=\pi / 2$ to $\theta=5 \pi / 2$. In view of the uncertainty in the conditions at location $\theta=\pi / 2$ (or $5 \pi / 2$ ), two models are considered:
A. Infinite (continuous) pad in $\theta$ direction;
B. Finite pad in $\theta$ direction. 
In the finite $\theta$ model, it is assumed that a narrow opening (slit) is formed at $\theta=\pi / 2$ (or $5 \pi / 2$ ) along the $z$ direction, and the pressure is fixed at atmospheric along this line regardless of the dynamics of the journal. In the continuous $\theta$ model, used by the authors previously [4-6, 12], there is no imposition of atmospheric pressure at $\theta=\pi / 2$ and the pressure there is wholly determined by the dynamics. It is expected that the real situation would be somewhere in between these two extremes.

Defining $\psi_{i, j}(\tau)=\psi\left(\xi_{i}, \theta_{j}, \tau\right)$ the partial derivatives in eq. (12) can be approximated using centraldifference formulae [12]:

$$
\begin{aligned}
& \left.\frac{\partial \psi}{\partial \theta}\right|_{i, j}=\frac{1}{2 \Delta \theta}\left(\psi_{i, j+1}-\psi_{i, j-1}\right),\left.\frac{\partial^{2} \psi}{\partial \theta^{2}}\right|_{i, j}=\frac{1}{\Delta \theta^{2}}\left(\psi_{i, j+1}-2 \psi_{i, j}+\psi_{i, j-1}\right) \\
& \left.\frac{\partial \psi}{\partial \xi}\right|_{i, j}=\frac{1}{2 \Delta \xi}\left(\psi_{i+1, j}-\psi_{i-1, j}\right),\left.\frac{\partial^{2} \psi}{\partial \xi^{2}}\right|_{i, j}=\frac{1}{\Delta \xi^{2}}\left(\psi_{i+1, j}-2 \psi_{i, j}+\psi_{i-1, j}\right)
\end{aligned}
$$

where, defining $\tilde{h}_{j}=\tilde{h}\left(\theta_{j}\right)$, the following boundary conditions are applied when calculating the derivatives at the edges of the grid:

$$
\begin{gathered}
\psi_{N_{z}+1, j}=\psi_{N_{z}-1, j}, \psi_{0, j}=\tilde{h}_{j} \\
\psi_{i, N_{\theta}+1}=\psi_{i, 1}, \psi_{i, 0}=\psi_{i, N_{\theta}} \text { (continuous } \theta \text { model) } \\
\psi_{i, N_{\theta}+1}=\tilde{h}(\theta=5 \pi / 2), \psi_{i, 0}=\tilde{h}(\theta=\pi / 2) \quad \text { (finite } \theta \text { model) }
\end{gathered}
$$

Eq. (15a) is due to symmetry and eq. (15b) is due to the open-atmosphere boundary condition at the bearing edges. Eqs. (16a,b) are due to periodicity in $\theta$ direction (in this case the grid extends from $\theta_{1}=\pi / 2$ to $\theta_{N_{\theta}}=5 \pi / 2-\Delta \theta$, to avoid duplication). Eqs. (17a,b) are due to the imposition of atmospheric pressure along the slit (in this case the grid extends from $\theta_{1}=\pi / 2+\Delta \theta$ to $\theta_{N_{\theta}}=5 \pi / 2-$ $\Delta \theta)$. In the simulations performed, the grid size was $7 \times 72$ in the case of the continuous $\theta$ model and $7 \times 71$ in the case of the finite $\theta$ model.

The values of $\tilde{h}$ and its derivatives at the grid points are: 


$$
\tilde{h}_{j}=1-\boldsymbol{\varepsilon}^{\mathrm{T}}\left[\begin{array}{c}
\cos \theta_{j} \\
\sin \theta_{j}
\end{array}\right]+\widetilde{w}_{j},\left.\frac{\partial \widetilde{h}}{\partial \theta}\right|_{j}=\boldsymbol{\varepsilon}^{\mathrm{T}}\left[\begin{array}{c}
\sin \theta_{j} \\
-\cos \theta_{j}
\end{array}\right]+\left.\frac{\partial \widetilde{w}}{\partial \theta}\right|_{j},\left.\frac{\partial^{2} \widetilde{h}}{\partial \theta^{2}}\right|_{j}=\boldsymbol{\varepsilon}^{\mathrm{T}}\left[\begin{array}{c}
\cos \theta_{j} \\
\sin \theta_{j}
\end{array}\right]+\left.\frac{\partial^{2} \widetilde{w}}{\partial \theta^{2}}\right|_{j}
$$

where $\widetilde{w}_{j}=\widetilde{w}(\theta)$ and is obtained by interpolation of the displacements at the apexes contained in the vector $\mathbf{w}_{\mathrm{p}}$, which itself is fully determined from the foil modal coordinate vector $\mathbf{q}_{\mathbf{f}}$, i.e.

$$
\widetilde{\mathbf{w}}=\left[\begin{array}{lll}
\cdots & \widetilde{w}_{j} & \cdots
\end{array}\right]^{\mathrm{T}}, \quad \widetilde{w}_{j}=\widetilde{w}_{j}\left(\mathbf{w}_{\mathrm{p}}\left(\mathbf{q}_{\mathrm{f}}\right)\right)
$$

The partial derivatives of $\widetilde{w}$ in eqs. $(18 \mathrm{~b}, \mathrm{c})$ are estimated as in eqs. (14a,b). Substituting eqs. (18a-c), together with the eqs. (14) into the RE (eq. (12)) yields the equation set (2a), which comprises $N_{z} N_{\theta}$ first order differential equations with $\tau$ as independent variable and $\boldsymbol{\psi}$ as the main state vector

$$
\boldsymbol{\Psi}(\tau)=\left[\begin{array}{lll}
\cdots & \psi_{i, j}(\tau) & \cdots
\end{array}\right]^{\mathrm{T}}
$$

The eqs (2a) are coupled to eqs (2b) and (2c) via the vectors $\mathbf{q}_{f}$ and $\mathbf{q}$. It is noted that in the air film force calculation (eqs. (5), (9b)), the gauge pressure $p-p_{\mathrm{a}} \equiv p_{\mathrm{a}} \times\left(\frac{\psi}{\tilde{h}}-1\right)$. Two alternative conditions are considered for the force calculation:

i. Full pressure condition (no truncation).

ii. Gümbel condition (truncation of pressures below atmospheric condition).

In the case of the Gümbel condition, in eqs. (5), (9b), $p$ is replaced by $p_{\text {trunc }}$ where $p_{\text {trunc }}=p_{\mathrm{a}}$ in those regions where $p<p_{\mathrm{a}}$ and $p_{\text {trunc }}=p$ elsewhere.

\subsection{Solution Process}

In the transient nonlinear dynamic analysis (TNDA), the time history of the unbalance response at fixed rotational speed was obtained by solving eqs. (2a-c) in Matlab using the implicit time domain integrator ode23s, which is a stiff solver with automatic time-step control for maintaining the numerical accuracy within a prescribed tolerance [14]. 
Prior to TNDA, an analysis for self-excited whirl was carried out (SESA, see Introduction) [6]. The static equilibrium condition at a given rotational speed was obtained by setting $\mathbf{s}^{\prime}=\mathbf{0}$ in eq. (1) and finding the solution $\mathbf{s}=\mathbf{s}_{\mathrm{E}}$ of the resulting system of nonlinear algebraic equations $\left.\boldsymbol{\chi}(\tau, \mathbf{s})\right|_{\mathbf{f}_{\mathrm{u}}=\mathbf{0}}=\mathbf{0}$. The stability of small perturbations about this condition was then assessed from the leading eigenvalue $\lambda_{\mathrm{L}}$ (eigenvalue with highest real part) of the Jacobian matrix $[5,6]$ :

$$
\left.\frac{\partial \chi}{\partial s}\right|_{f_{u}=0, s=s_{E}}
$$

where the perturbation will be unstable for $\operatorname{Re}\left\{\lambda_{\mathrm{L}}\right\}>0$ and the ratio of its frequency to rotational speed given by $\operatorname{Im}\left\{\left|\lambda_{\mathrm{L}} / 2\right|\right\}[6]$.

\section{PRESENTATION OF RESULTS AND DISCUSSION}

In this section, the results of preliminary simulations are first discussed (section 4.1). Experimental and theoretical unbalance response results are then correlated (section 4.2). The section concludes with a note on the post-experiment bearing condition (section 4.3).

\subsection{Preliminary Simulations}

With reference to the air film model of section 3.3, the calculations considered four possible combinations of boundary conditions for the air film:

(1) continuous $\theta$ pad with no pressure truncation (“non-Gümbel”) i.e. combining conditions (A) and (i) in section 3.3;

(2) finite $\theta$ pad with no pressure truncation (“non-Gümbel”) i.e. combining (B) and (i) in section 3.3;

(3) continuous $\theta$ pad with pressure truncation (“Gümbel”) i.e. combining (A) and (ii);

(4) finite $\theta$ pad with Gümbel condition i.e. combining (B) and (ii).

Figure 6 shows the SESA results obtained with the continuous $\theta$ non-Gümbel air film model. The onset of instability (OIS) speed is here defined as the first speed, in steps of $500 \mathrm{rpm}$, to register a leading eigenvalue $\lambda_{\mathrm{L}}$ with positive real part (Hopf bifurcation [13]). Figure 6(a) shows the OIS to be $9 \mathrm{krpm}$ and 
Figure 6(b) shows that the frequency of the divergent perturbation at the OIS is 0.43EO, where 1EO (“Engine Order”) denotes a synchronous frequency.

\section{Figure 6 here}

The results of Figure 6 were verified against TNDA with no applied rotational unbalance. Figure 7(a) shows the convergence of the journal trajectory at $8.5 \mathrm{krpm}$ towards the stable static equilibrium position (SEP) from initial conditions corresponding to the SEP at $6 \mathrm{krpm}$. In Figure 7(b) the speed is $9 \mathrm{krpm}$ (OIS) and the initial conditions correspond to those of the stable SEP at $8.5 \mathrm{krpm}$ (which is slightly displaced from the SEP at $9 \mathrm{krpm})$. Over the course of 400 shaft revolutions the trajectory is seen to diverge from the SEP and converge towards a steady-state self-excited oscillation of fixed amplitude (limit cycle). Figure 7(c) shows the Fast Fourier Transform of the limit cycle. Its fundamental frequency is 0.49EO. Note that the whirl frequency of the divergent perturbation predicted by SESA was 0.43EO (Figure 6(b)) but, as already observed by Bonello and Pham in [6], the whirl frequency from the (linear) stability analysis refers to the perturbation in the immediate vicinity of the SEP i.e. the early transient stage in Figure 7(b). The fundamental frequency of the final limit cycle will be somewhat different, depending on how far it is from the unstable SEP. As observed in the cases studied in [6], the fundamental frequency of the limit cycle is higher than that of the initial divergent perturbation. It is noted that the spectrum also contains a frequency component that is practically synchronous (0.97EO). This is not due to unbalance (which is zero) but is the second harmonic of the fundamental. It is also interesting to note that when the TNDA was run at different fixed speeds with initial conditions corresponding to the limit cycle at $9 \mathrm{krpm}$, the trajectory did not collapse back to the stable SEP at 8.5 krpm, but at lower speed of 8 krpm. This "hysteresis" between run-up and coast-down means that at 8.5 krpm there are two possible steady-state conditions - either a stable SEP or a limit cycle - that can be reached by different initial conditions. This is to be expected from a speed that this close to the stability threshold (Figure 6(a)). 
In view of the uncertainty in the nominal radial clearance, the effect of a variability of $\pm 20 \%$ was investigated. As seen from Figure 8, the corresponding variability in OIS was $\pm 500 \mathrm{rpm}$ and the ratio of the fundamental frequency of the limit cycle to the rotational speed remained $\sim 0.5$. A variability of $\pm 50 \%$ in the foil damping ratio was also investigated but negligible effect on the simulations was observed.

\section{Figure 7 here}

\section{Figure 8 here}

Figure 9 shows the loci of the predicted static equilibrium positions of the FAB journal over the operating speed range according to the four combinations of air film boundary conditions listed above. It is evident that the imposition of pressure constraints on the air film (fixed atmospheric pressure line at $\theta=\pi / 2$ and/or lower limit set at atmospheric pressure for the pressure) generally results in an increase in the OIS. Comparing Figure 9(b) with 9(a), the finite $\theta$ condition delays the OIS to $11 \mathrm{krpm}$ (from $9 \mathrm{krpm}$ ) but otherwise has a relatively slight effect on the SEP locus. The main effect comes from the imposition of the Gümbel condition, which lowers the SEPs and significantly delays the OIS (compare Figures 9(c,d) with 9(a,b)). Notice the OSI in Figure 9(d) of $15 \mathrm{krpm}$ correlates well with that predicted in [9] (15.4 krpm) for a FAB with similar dimensions and static load (15 $\mathrm{N}$ compared to $13.9 \mathrm{~N}$ in the present case). The application of the TNDA at zero unbalance for each case at the respective OIS yielded a limit cycle with fundamental frequency of $\sim 0.5 \mathrm{EO}$ every time. The subsequent simulations shall focus on the two alternative air film constraint combinations typically used for the simultaneous solution schemes:

(a) continuous $\theta$, non-Gümbel, Figure 9(a) (as used by Bonello et al. [4-6, 12]);

(b) finite $\theta$ with Gümbel, Figure 9(d) (as used in [10, 11, 16], [17]). 


\section{Figure 9 here}

Prior to presenting further results, the effect of the number of rotor modes used in the computation is examined. Figure 10 shows the steady-state operating deflection shape (ODS) for a disc unbalance of 10 g.mm at two different speeds. At $15 \mathrm{krpm}$, the exclusion of the bending mode in each plane $x z, y z$ makes little difference to the ODS. However, at speeds beyond 20 krpm the inclusion of the bending mode has a visible effect on the ODS. It is noted that the FAB forces on the rotor are the only significant source of damping. Hence, the component of the vibration associated with the bending mode has very little effective damping since the FAB force location is only $1 \mathrm{~mm}$ away from the node of the bending mode (at $479 \mathrm{~Hz}$, see Figure 5). The associated modal FAB forces were consequently miniscule, but were found to be just enough to attenuate the transient free vibration contribution from the bending mode equations in eq. (2c) for speeds up to $29 \mathrm{krpm}(483 \mathrm{~Hz})$. This speed, at which the amplitude of the 1EO frequency rises suddenly, is very close to the first bending critical speed of the rotor-bearing system and it was not possible to traverse it in simulation due to the ineffectiveness of the FAB forces in the bending mode. The very close proximity of the node (Figure 5) to the FAB means that, in the absence of significant gyroscopic effects, the bending mode of the linear part (pinned-free, $479 \mathrm{~Hz}$ ) would be very close to the bending critical speed of the full rotor-FAB system.

\section{Figure 10 here}

\subsection{Experimentation and Correlation with Theoretical Results}

The measured vibration data at the disc location (Figure 2) were acquired and analysed by a multichannel data acquisition system and associated software. For each given unbalance level, the procedure for the experimental run was as follows. After the rig was started up (and auxiliary motor disengaged, if used), the valve controlling the air motor (pressure regulator) was set to allow the rig to run at constant speed for 1-2 minutes. The data recording was then commenced at this constant speed. With reference to 
Figure 11(a), that shows the speed probe reading for the run at the residual unbalance level, data were acquired at this constant speed for around $4 \mathrm{~s}$ (point (1) to (2)). The valve of the air motor was then fully opened and the rig allowed to accelerate. This run-up took approximately $6 \mathrm{~s}$ (point (2) to (3)) to reach the maximum speed of 27,456 rpm (458 rev/s). The rotor was maintained at this top speed for about $3 \mathrm{~s}$ (point (3) to (4)) before the valve was immediately closed, to record the coast-down signal. The coastdown to rest took $10 \mathrm{~s}$ (point (4) to (5)). The total length of the measurement in Figure 11(a) was about 25 s. The maximum achievable top speed (pressure regulator fully opened) never exceeded $\sim 28 \mathrm{krpm}$ for all unbalance levels. The likely reason for this is that this speed is close to the bending critical. The ineffectiveness of the FAB forces due to their proximity to the node means that, close to this speed, there must have been excessive rocking at the FAB (pivoting in the planes $x z, y z$ ) and consequent rubbing of the journal with the bearing edges, resulting in a braking torque.

\section{Figure 11 here}

Figures 11(b,c) show the spectrogram (time-varying frequency spectrum) of the $y$-vibration for the case of no added unbalance (residual), corresponding to the rotational speed variation of Figure 11(a). The amplitude of the $1 \mathrm{EO}$ component is seen to rise suddenly just before the top speed (458 rev/s) is reached, confirming that the bending critical is close. The top speed is in fact within $6 \%$ of the predicted and measured frequencies of the bending mode of the linear part (479, $489 \mathrm{~Hz}$ respectively) which was predicted to be very close to the bending critical (end of previous section). It is also evident that on runup, a sub-synchronous frequency emerges beyond a certain speed. As predicted, this frequency is half the rotational speed (0.5EO). Moreover, it tracks the rotational speed at this constant ratio (0.5EO) until it disappears before the top speed is reached. As soon as coast-down commences, a pair of subsynchronous frequencies appear that immediately merge into one frequency that tracks the speed, initially along a $0.33 \mathrm{EO}$ line, before shifting (via bifurcation) to the $0.5 \mathrm{EO}$ line and eventually disappearing. This is illustrated more clearly in the measured waterfall diagrams of Figures 12(a,b) and Figures 12(c,d), 
which refer to the $x, y$ vibrations on run-up and coast-down respectively. Comparing Figures 12(a,b) with $12(\mathrm{c}, \mathrm{d})$ it is seen that the speed at which the 0.5EO appears on run-up $(12.5 \mathrm{krpm})$ is higher than the speed at which the 0.5EO disappears on coast-down $(11.5 \mathrm{krpm})$. This is consistent with the observations on the predictions made in the discussion around Figure 7 (relating to "hysteresis"). The run-up measurements feature only 0.5EO as sub-synchronous frequencies, whereas the coast-down feature 0.33EO (and faint multiples 0.67EO) succeeded by 0.5EO. Figures 12(e,f) show the predicted $x, y$ waterfall diagrams, which feature the $0.5 \mathrm{EO}$ as the only significant frequency. Notice that these predictions were made for zero unbalance, hence the vibration starts at the OSI (9 krpm) and is pure selfexcitation. The $1 \mathrm{EO}$ and other faint frequencies in the prediction are purely attributed to the presence of harmonics of the fundamental frequency (0.5EO) of the non-linear oscillation. The stronger 1EO in the measured waterfall diagrams is due to the actual residual unbalance and run-out. The latter effect will be discussed later and is mainly responsible for the measured vibration being larger than the predictions (as in [11]).

It should be noted that the measured waterfall diagrams were computed by the data analyser software under variable speed conditions with a frequency resolution of $2.5 \mathrm{~Hz}$, whereas the predictions were computed from steady-state vibration data at fixed speeds. For each fixed speed, the TNDA was run over a time interval covering 450 shaft revolutions, of which only the last $0.5 \mathrm{~s}$ of data were retained. This guaranteed steady-state data from which a frequency spectrum with resolution of $2 \mathrm{~Hz}$ could be computed at each speed. Hence, the discarded data ranged from 433 revolutions at the lowest speed (2 krpm) to 208 revolutions at the highest speed $(29 \mathrm{krpm})$. Also, the predicted spectra shown are for run-up (TNDA initial conditions at a fixed speed were inherited from the previous speed). The predicted spectra for runup and coast-down were found to be practically identical except for the slight hysteresis in the appearance/disappearance of the 0.5EO on run-up/coast-down mentioned earlier.

Figure 13 presents the measured and predicted waterfall diagrams for 5 g.mm added unbalance. Comparing Figures 13(a,b) with Figures 12(a,b), it is seen that, in the case of the measured run-up results, 
the addition of unbalance had a significant effect - the appearance of a 0.33EO frequency train (along with a weaker multiples $0.67 \mathrm{EO}$ ) that appear after the disappearance of the $0.5 \mathrm{EO}$ train. This means that the measured run-up results at 5 g.mm (Figure 13(a,b)) are closer in appearance to the measured coastdown results at both 5 g.mm (Figure 13(c,d)) and residual unbalance (Figure 12(c,d)). With regard to the predictions, the addition of 5 g.mm unbalance (Figures 13(e,f)) did not have much of an effect (compare with Figure 12(e,f)) other than the expected strengthening of the amplitudes of the 1EO frequency train.

Figures 14(a,b),(c,d) show that further increase of the unbalance level to 10 g.mm retains the same major frequency trains in the measurements $(0.5 \mathrm{EO}, 0.33 \mathrm{EO}, 1 \mathrm{EO})$ and strengthens the 0.67EO train in the $y$ vibration spectra on run-up. It is noted that the shift from $0.5 \mathrm{EO}$ to $0.33 \mathrm{EO}$ on run-up tends to be abrupt (Figure 14(a,b)), whereas the shift from 0.33EO to 0.5EO on coast down tends to be more gradual (Figure 14(c,d)). The shift occurs at a lower speed on run-up (16 krpm) than coast-down (18 krpm). With regard to the predictions, it is seen from Figures 14(e,f) that the increase in unbalance level to 10 g.mm results in the appearance of $0.33 \mathrm{EO}$ and $0.67 \mathrm{EO}$ frequency trains. These predictions exhibit all the major subsynchronous frequency trains $(0.5 \mathrm{EO}, 0.33 \mathrm{EO}$ and $0.67 \mathrm{EO})$ in the measurements and the experimentally observed trend for the $0.5 \mathrm{EO}$ to shift to $0.33 \mathrm{EO}$ above a certain speed. The predicted 0.5EO frequency train lasts from $9 \mathrm{krpm}$ to $19 \mathrm{krpm}$ (compared with 10-18 krpm range of the 0.5EO measured on coast-down). Beyond this speed, the predicted 0.5EO train disappears abruptly and is replaced by strong $0.33 \mathrm{EO}$ and $0.67 \mathrm{EO}$ trains, as in the measured run-up waterfall diagram (Figure 14(a,b)). However, the predicted evolution of these two frequency trains is somewhat different from experiment. According to the predictions, the $0.33 \mathrm{EO}$ and $0.67 \mathrm{EO}$ exist from $19.5 \mathrm{krpm}$ to $22 \mathrm{krpm}$. The predicted 0.33EO disappears thereafter and the frequencies previously on the 0.67EO train shift gradually such that their frequency to speed ratio decreases, eventually becoming $0.5 \mathrm{EO}$ from $27.5 \mathrm{krpm}$ onwards. Moreover, the predicted amplitudes of the 0.67EO are of similar strength to the 0.33EO amplitudes, whereas the measured 0.67EO are much weaker.

\section{Figures 12, 13, 14 here}


The coast-down measurements of Figures 12(c,d), 13(c,d), 14(c,d) show that the speed at which the subsynchronous activity disappears decreases marginally from $11.5 \mathrm{krpm}$ to $10 \mathrm{krpm}$ as the unbalance was raised to 10 g.mm. Likewise, the run-up measurements of Figures 12(a,b), 13(a,b) show that the speed at which the sub-synchronous activity appears decreases slightly from $12.5 \mathrm{krpm}$ to $11.5 \mathrm{krpm}$ as the unbalance is raised to 5 g.mm (unfortunately the run-up measurements at 10 g.mm (Figures 14(a,b)) were recorded from a speed higher than the onset speed of the 0.5EO). With regards to the predictions of Figures 12(e,f), 13(e,f), 14(e,f), which were obtained with the continuous $\theta$, non-Gümbel air film conditions, the onset speed of the 0.5EO was not affected by the unbalance level, within a resolution of $0.5 \mathrm{krpm}$, remaining at the OIS of $9 \mathrm{krpm}$. However, when the finite $\theta$, Gümbel conditions were used, the onset speed for sub-synchronous activity was affected by unbalance to a greater extent than observed in the measurement (see Figures 15(a,b)). At very low unbalance (1 g.mm, Figure 15(a)), subsynchronous activity starts at $15 \mathrm{krpm}$ (the OIS predicted in Figure 9(d)) and consists of pair of frequencies $0.46 \mathrm{EO}$ and $0.54 \mathrm{EO}$ that average to $0.5 \mathrm{EO}$, with the $0.46 \mathrm{EO}$ being the major frequency. When the unbalance was increased to 5 g.mm (Figure 15(b)), the onset speed of sub-synchronous activity decreased to $12 \mathrm{krpm}$ and resulted in a single train that tracked the speed at 0.5EO exactly. Moreover, as can be seen from Figure 15, for speeds beyond $17 \mathrm{krpm}$, it was not possible to generate steady-state predictions due to numerical instability (likely caused by a negative film thickness). It appears that this problem has also been encountered by other researchers who used the finite $\theta$, Gümbel conditions, or equivalent, at speeds beyond the OIS [11, 17]. In fact, the operating speed ranges considered in [11] and [17] were within the linear stability regime.

\section{Figure 15 here}

Figures 16, 17 compare orbits that were measured and predicted at the disc over a range of speeds at 10 g.mm unbalance. Figure 16 shows orbits in the range $4-12 \mathrm{krpm}$, with the first column showing the measurement and the second two columns showing predictions obtained respectively with continuous $\theta$, 
non-Gümbel conditions and finite $\theta$, Gümbel conditions. Each graph also indicates the lowest significant frequency component in the vibration spectrum. Figure 17 shows the same for $13-26 \mathrm{krpm}$. Each predicted orbit covers the last 50 out of 450 shaft revolutions at fixed speed, whereas the measured orbits were extracted under variable speed conditions (coast-down) at the average speeds indicated. The measured orbits are seen to be significantly larger than predicted. Apart from the effect of residual unbalance, another major reason for this discrepancy is shaft run-out at the measurement position. In this context, run-out is that part of the signal that is picked up by the displacement probes which is not due to vibration or not caused by the excitations considered. This may be caused by machining irregularity of the disc surface profile. Another cause can be misalignment, and consequent bending moment effect from the coupling, which results in a variable tilt as the shaft is rotated. Larsen and Santos [11] also experienced a considerable difference between measured and predicted amplitudes (especially at residual unbalance) which they attributed to run-out. The measured "orbit” at 4 krpm (Figure 16(a)) is in fact the run-out profile since it was found to remain practically unchanged (in all its detail) when the speed was reduced to $2 \mathrm{krpm}$ and/or the added unbalance completely removed. Run-out also contributes to the relatively weak 2EO and 3EO frequency components in the measured spectra of Figures 12-14 [11]. As can be seen from Figure 17, no predictions by the finite $\theta$, Gümbel (FTG) conditions were possible above $17 \mathrm{krpm}$, as already mentioned when discussing the waterfall diagrams of Figure 15. On the other hand, certain orbits predicted by the continuous $\theta$, non-Gümbel (CTNG) conditions in Figures 16, 17 show remarkable similarity to the measurements e.g. the vertically-oriented, approximately elliptical shape at 8 krpm (Figures 16(a,b)); the orientation and profile of the period-two (0.5EO fundamental) orbit at 15 krpm (Figures 17(a,b)), where the location of the kink in the CTNG-predicted orbit matches with that of the loop in the corresponding measured orbit); the period-three orbits at 20, $21 \mathrm{krpm}$ (Figures 17(a,b)).

\section{Figures 16, 17 here}




\subsection{Discussion of Results}

From the results in Figures 12-17, it is clear that the predictions by the CTNG conditions generally provide better correlation with the measurements, compared to the predictions by the FTG conditions. The main difference between the CTNG and the FTG is the imposition of the Gümbel condition (Figure 9). Since the FAB used in the test rig was a single-pad FAB with a free leading edge/clamped trailing edge (FLE/CTE), the above findings are consistent with the theoretically-derived claim made by Nielsen [19] that the imposition of the Gümbel condition may not be appropriate for a single-pad FAB operating in this mode. It is also noted that further simulations were conducted with finite $\theta$, non-Gümbel conditions and these were found to be largely similar to those obtained with continuous $\theta$, non-Gümbel conditions, as expected from Figures 9(a,b). However, the finite $\theta$, non-Gümbel predictions exhibited numerical instability at high speeds for high unbalance (10 g.mm). In this case, the imposition of a fixed pressure at $\theta=\pi / 2$, independent of the journal dynamics, may be unrealistic in practice at high levels of vibration.

Both experiments and predictions show a large amplitude 0.5EO frequency appearing above a certain speed and its bifurcation to vibration with 0.33EO fundamental frequency as the speed was increased further. According to the predictions, the 0.5EO was due to self-excitation (instability), whereas the 0.33EO and related $0.67 \mathrm{EO}$ vibration were the products of forced nonlinearity at high unbalance. This observation was consistent with the measured run-up, which showed only $0.5 \mathrm{EO}$ at residual unbalance (Figures 12(a,b)) and both 0.5EO and 0.33EO at higher unbalance (Figures 13(a,b)). However the coastdown at residual unbalance also exhibited a 0.33EO (Figures 12(c,d)) and it cannot be conclusively proven that the observed 0.5EO was the result of pure self-excitation since perfect balance cannot be achieved in practice.

Nonetheless, whether forced or self-excited, the predicted nonlinear phenomena are attributed to the air film, which is the only source of nonlinearity in the present model. This contrasts with the findings of San Andres and Kim [24], whose experiments revealed remarkably similar behavior (1EO to 0.5EO to 0.33EO) over similar speed range $(10-30 \mathrm{krpm})$ but which was predicted with a model that completely 
ignored the air film and used an experimentally determined nonlinear spring model for the foil. Hence, their conclusion that the nonlinear phenomena were not related to the air film, and that this could be assumed to have an infinite stiffness, should not be regarded as universal. Even more so because the infinite film stiffness assumption requires asymptotically high speeds in theory [3] and was not found to be particularly satisfactory by other researchers [3] who used it at much higher speeds.

\subsection{Examination of Bearing Condition}

In order to ensure that the FAB was still in good condition after the extensive experimental testing, its condition was compared with that of a nominally identical brand new FAB in two ways: (i) impact testing the rig with the old/new FAB in place - to ascertain that the foil retained its elasticity; (ii) visual inspection for signs of wear. With regards to the impact testing, for each FAB in turn, two FRFs (relating the impact point with two different response locations no.1, no.2) were obtained. As can be seen from Figure 18, the FRF no.1 with the old FAB agreed very closely with the same FRF obtained with the new FAB. The same can be said for FRF no.2, confirming that the old FAB retained its compliance. It is also worth noting that the first bending mode of the rotor-FAB system was practically the same as the “pinned-free” mode of section $2.2(\sim 489 \mathrm{~Hz})$ since the FAB was located at the nodal position.

\section{Figure 18 here}

From the physical inspection on the used FAB (Figure 19), the wear on the top foil was concentrated at the bearing edges, which agrees with [26]. There are two reasons for this: the pressure dropping to ambient at the edges of the bearing, resulting in reduced deflection; shaft tilt (misalignment, and rocking when approaching the bending critical). The marks also show that the wear on the top foil occurs mainly at the points where it is supported by the bump foil i.e. the apexes. This indicates localised stiffness at the 
apexes (directly from the bumps) alternating with regions of lower stiffness (in-between the apexes). Such observations were not accounted for in the foil model used.

\section{Figure 19 here}

\section{CONCLUSIONS}

This paper has presented an experimental and theoretical study of a FAB-rotor system. The simultaneous solution technique used a recently introduced modal-based bump foil model that accounted for dynamic interaction between the bumps and their inertia. A variety of air film boundary conditions were considered. The imposition of pressure constraints on the air film was found to delay the predicted onset of instability speed. The results lend experimental validation to a recent theoretical finding that the imposition of the Gümbel condition may not be appropriate for practical single-pad FABs, which use a clamped trailing edge (and free leading edge) to ensure safe operation. It is also interesting to note that, if a single-pad FAB can be designed and manufactured to ensure safe service in the reverse operating mode (i.e. a free trailing edge and clamped leading edge), then, for the rotor system studied, it is predicted to benefit from delayed onset of instability speed, since the Gümbel condition would then be applicable.

The salient features of the observed nonlinear phenomena were satisfactorily predicted using a theoretical model in which the air film was the only source of nonlinearity. This contradicts the findings by previous researchers who completely ignored the air film without theoretical justification and attributed the observed nonlinear effects to nonlinearities in the foil structure.

Notwithstanding overall satisfactory correlation between measurements and predictions, evident discrepancies and the post-experiment bearing inspection indicate the need to refine the model, for example by combining the modal bump foil model (as used here) with a recently proposed detachable top foil model, among other improvements. 


\section{ACKNOWLEDGMENTS}

The authors acknowledge The Ministry of Education Malaysia and University of Malaysia Pahang, for their financial support. The authors also acknowledge the contribution of $\mathrm{Dr}$ Pham Minh Hai in designing and building the test rig through a previous project EPSRC EP/I029184/1 and the Engineering and Physical Sciences Research Council for funding EP/I029184/1. Data related to the research presented in this paper shall be made available through the University of Manchester's publications repository.

\section{Appendix A - Rotor Details}

The geometric and physical parameters of the rotor are as shown in Figure A1.

\section{Figure A1 here}

\section{REFERENCES}

[1] G.L. Agrawal, Foil Air/Gas Bearing Technology - An Overview, in: Proceedings of the ASME Turbo Expo, 1997, Orlando, Florida, USA, paper no. 97-GT-347.

[2] M.J. Valco, C. DellaCorte, Emerging Oil-Free Turbomachinery Technology for Military Propulsion and Power Applications, in: Proceedings of the 23rd U. S. Army Science Conference, 2002, Ft. Lauderdale, FL, USA, 2-5 December 2002.

[3] F. Balducchi, M. Arghir, Gauthier, R., Experimental analysis of the unbalance response of rigid rotors supported on aerodynamic foil bearings, Journal of Vibration and Acoustics 137 (6) (2015) 061014.

[4] M.F. Bin Hassan, P. Bonello, A new modal-based approach for modelling the bump foil structure in the simultaneous solution of foil-air bearing rotor dynamic problems, Journal of Sound and Vibration 396 (2017) 255-273, doi: 10.1016/j.jsv.2017.02.028.

[5] P. Bonello, H. M. Pham, The efficient computation of the nonlinear dynamic response of a foil-air bearing rotor system, Journal of Sound and Vibration 333 (15) (2014) 3459-3478, doi: 10.1016/j.jsv.2014.03.001. 
[6] P. Bonello, H. M. Pham, Nonlinear dynamic analysis of high speed oil-free turbomachinery with focus on stability and self-excited vibration, Journal of Tribology 136(4) (2014) 041705, doi:10.1115/1.4027859.

[7] D. Kim, Parametric studies on static and dynamic performance of air foil bearings with different top foil geometries and bump stiffness distributions, Journal of Tribology 129 (2) (2007) 354-364, doi:10.1115/1.2540065.

[8] S. Le Lez, M. Arghir, J. Frêne, Nonlinear numerical prediction of gas foil bearing stability and unbalanced response, Journal of Engineering for Gas Turbines and Power 131 (1) (2009) 012503, doi:10.1115/1.2967481.

[9] R. Hoffmann, T. Pronobis, R. Liebich, Non-linear stability analysis of a modified gas foil bearing structure, in: Proceedings of the 9th IFToMM International Conference on Rotor Dynamics, 2015, pp. 1259-1276, http://dx.doi.org/10.1007/978-3-319-06590-8_103.

[10] J.S. Larsen, B.B. Nielsen, I.F. Santos, On the Numerical Simulation of Nonlinear Transient Behaviour of Compliant Air-Foil Bearings, in: Proceedings of SIRM 2015, Magdeburg, Deutschland, 2015, Paper-ID 39.

[11] J.S. Larsen, I.F. Santos, On the nonlinear steady-state response of rigid rotors supported by air foil bearings - Theory and experiments, Journal of Sound and Vibration 346 (2015) 284-297, doi:10.1016/j.jsv.2015.02.017.

[12] H.M. Pham, P. Bonello, Efficient Techniques for the Computation of the Nonlinear Dynamics of a Foil-Air Bearing-Rotor System, in: Proceedings of the ASME Turbo Expo, 2013, San Antonio, Texas, USA, paper no. GT-2013-94389.

[13] E. Ott, Chaos in Dynamical Systems, Cambridge University Press, Cambridge, 1993.

[14] L. F. Shampine, M. W. Reichelt, The Matlab ODE suite, SIAM J. Sci. Comput. 18 (1) (1997) 122. 
[15] J.W. Lund, Calculation of stiffness and damping properties of gas bearings, Journal of Lubrication Technology (1968) 793-804.

[16] J.S. Larsen, I.F. Santos, S. von Osmanski, Stability of rigid rotors supported by air foil bearings: Comparison of two fundamental approaches, Journal of Sound and Vibration 381 (2016) 179-191, doi:10.1016/j.jsv.2016.06.022

[17] B.B. Nielsen, I.F. Santos, Transient and steady state behaviour of elasto-aerodynamic air foil bearings, considering bump foil compliance and top foil inertia and flexibility: a numerical investigation, Proc. IMechE Part J: Journal of Engineering Tribology (2017), doi: 10.1177/1350650117689985.

[18] J.S. Larsen, Nonlinear Analysis of Rotors Supported by Air Foil Journal Bearings - Theory and Experiments, Ph.D. thesis, DTU Mechanical Engineering, DCAMM Special Report, no. S177, ISBN 978-87-7475-402-2, Technical University of Denmark, Lingby, Denmark, 2014.

[19] B. B. Nielsen, Combining Gas Bearing and Smart Material Technologies for Improved Machine Performance: Theory and Experiment, Ph.D. thesis, DTU Mechanical Engineering. DCAMM Special Report, no. S221, ISBN 978-87-7475-481-7 Technical University of Denmark, Lingby, Denmark, 2017.

[20] R. Hoffmann, T. Pronobis, R. Liebich, A Numerical Performance Analysis of a Gas Foil Bearing Including Structural Modifications by Applying Metal Shims, in: Proceedings of SIRM 2015, Magdeburg, Deutschland, 2015, Paper-ID 49.

[21] H. Heshmat, Advancements in the performance of aerodynamic foil journal bearings: high speed and load capability, Journal of Tribology 116 (2) (1994) 287-294.

[22] H. Heshmat, Operation of foil bearings beyond the bending critical mode, Journal of Tribology 122 (1) (2000) 192-198. 
[23] B.S. Choe, T.H. Kim, C. H., Kim, Y.B. Lee, Rotordynamic behavior of 225 kW (300 HP) class PMS motor-generator system supported by gas foil Bearings, Journal of Engineering for Gas Turbines and Power 137 (9) (2015) 092505.

[24] L. San Andres, T.H. Kim, Forced nonlinear response of gas foil bearing supported rotors, Tribology International 41 (8) (2008) 704-715.

[25] D. Ruscitto, J. McCormick, S. Gray, Hydrodynamic air lubricated compliant surface bearing for an automotive gas turbine engine - I - journal bearing performance, NASA (1978). (Technical Report No. CR-135368).

[26] L. San Andrés, D. Rubio, T.H. Kim, Rotordynamic performance of a rotor supported on bump type foil gas bearings: experiments and predictions, Journal of Engineering for Gas Turbines and Power 129 (3) (2007) 850-857.

[27] ISO Standard, 1940-1: 2003 Mechanical Vibration-Balance Quality Requirements for Rotors in a Constant (Rigid) State-Part 1: Specification and Verification of Balance Tolerances, International Organisation for Standardization, https://www.iso.org/standard/27092.html.

[28] M.L. Adams, Non-linear dynamics of flexible multi-bearing rotors, Journal of Sound and Vibration 71 (1) (1980) 129-144.

[29] P. Bonello, P., Transient Modal Analysis of the Nonlinear Dynamics of a Turbocharger on Floating Ring Bearings, Proc. IMechE Part J: Journal of Engineering Tribology 223 (2009) 79-93.

[30] S. von Osmanski, J.S. Larsen, I.F. Santos, A fully coupled air foil bearing model considering friction - theory and experiment, Journal of Sound and Vibration 400 (2017) 660-679. 


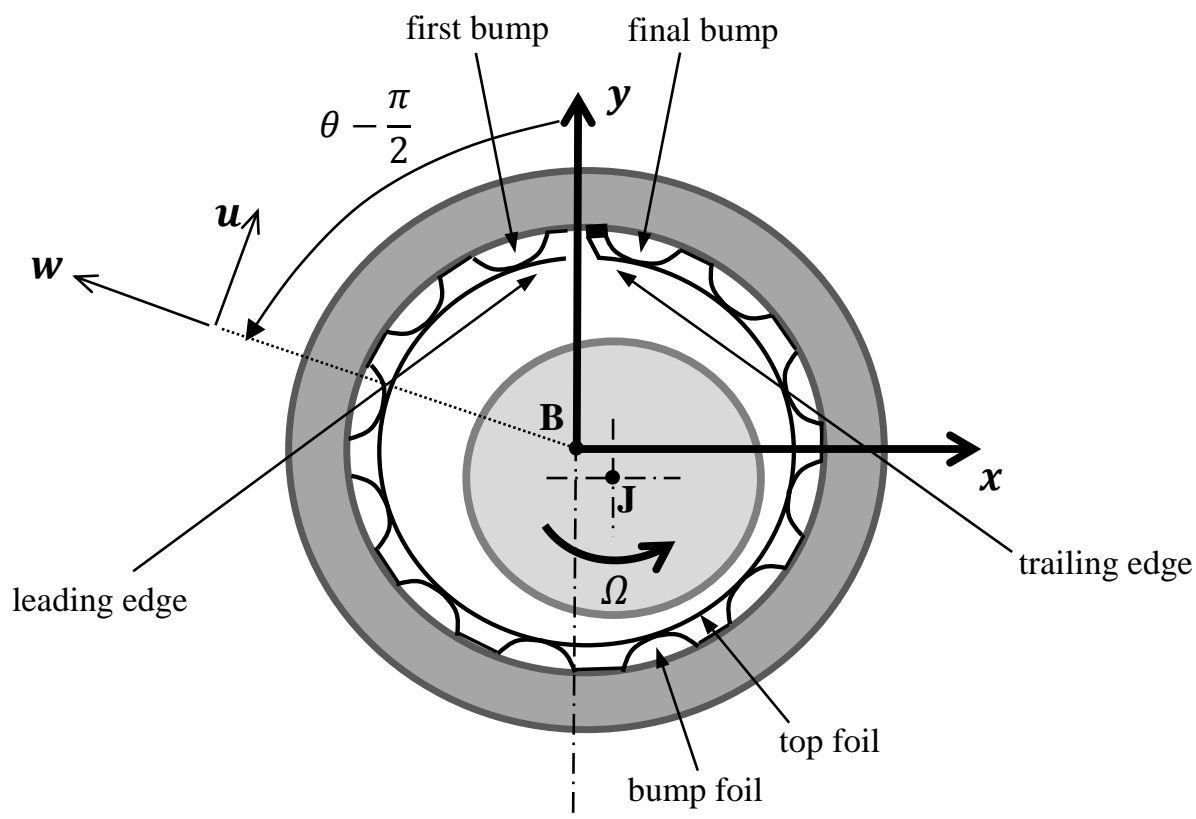

Figure 1. Foil air bearing (FAB). 
(a)

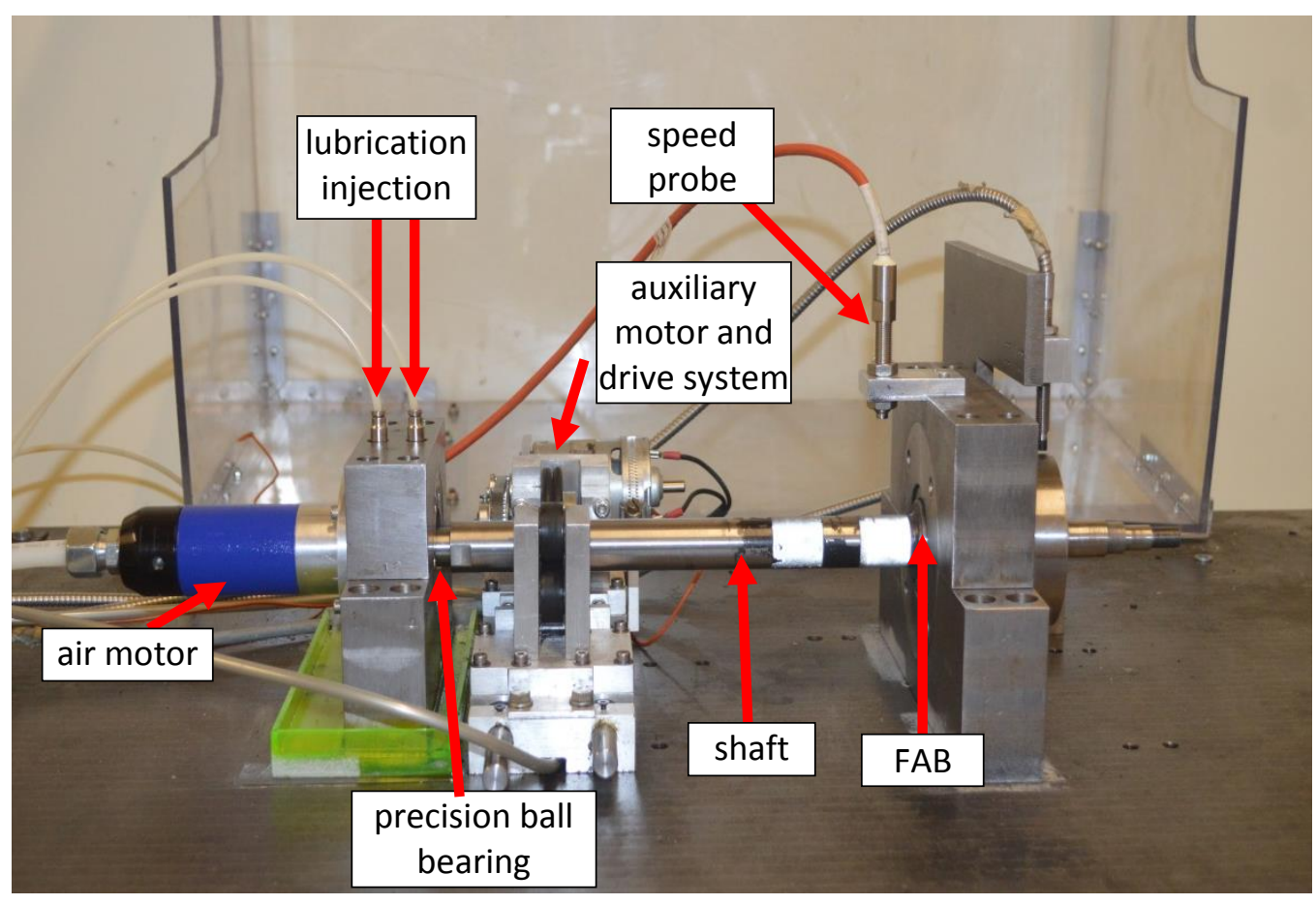

(b)

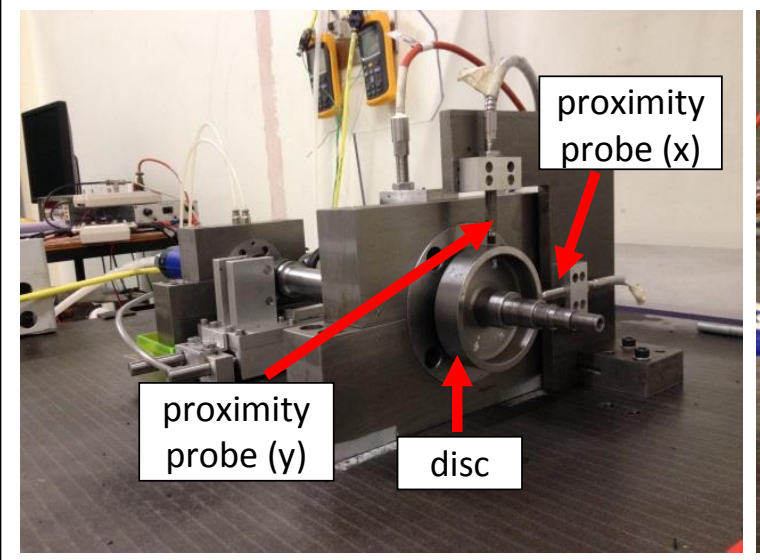

(c)

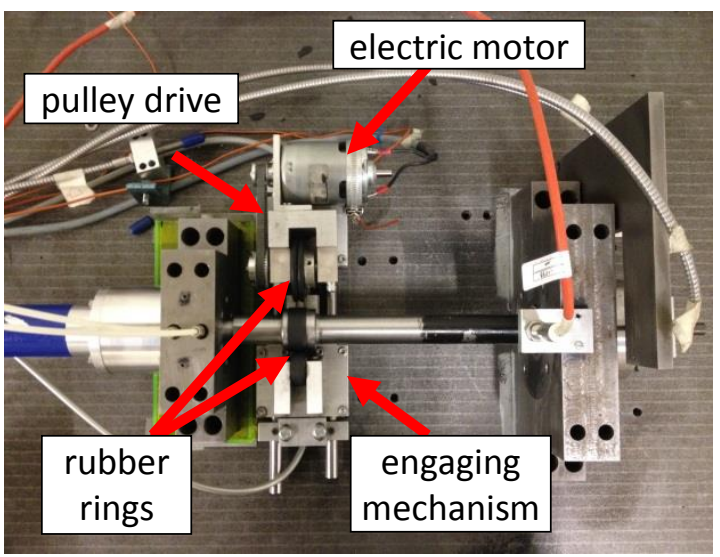

Figure 2. Test rig photographs: (a) front view; (b) isometric; (c) top view 


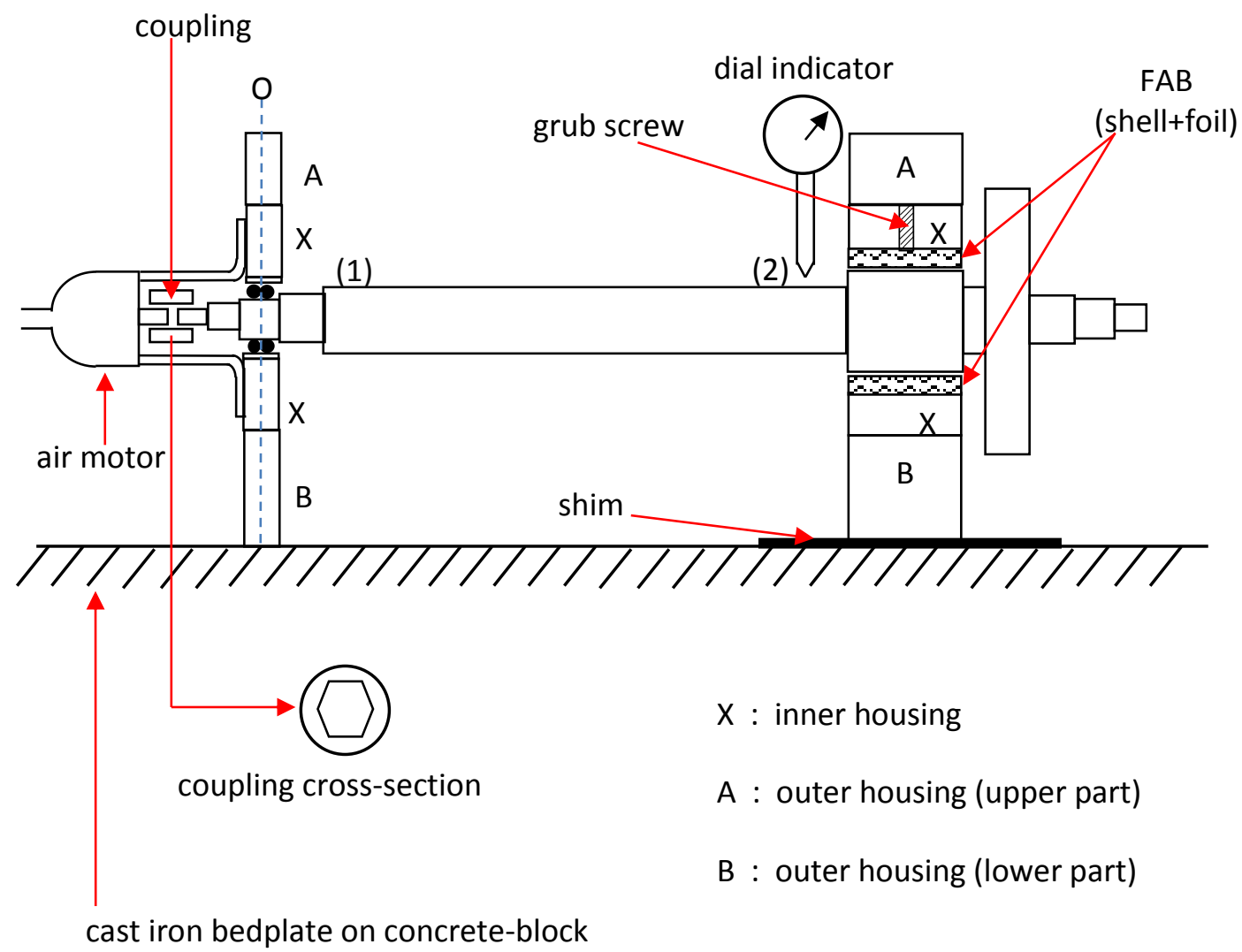

Figure 3. Test rig schematic showing shaft alignment procedure. 
(a)

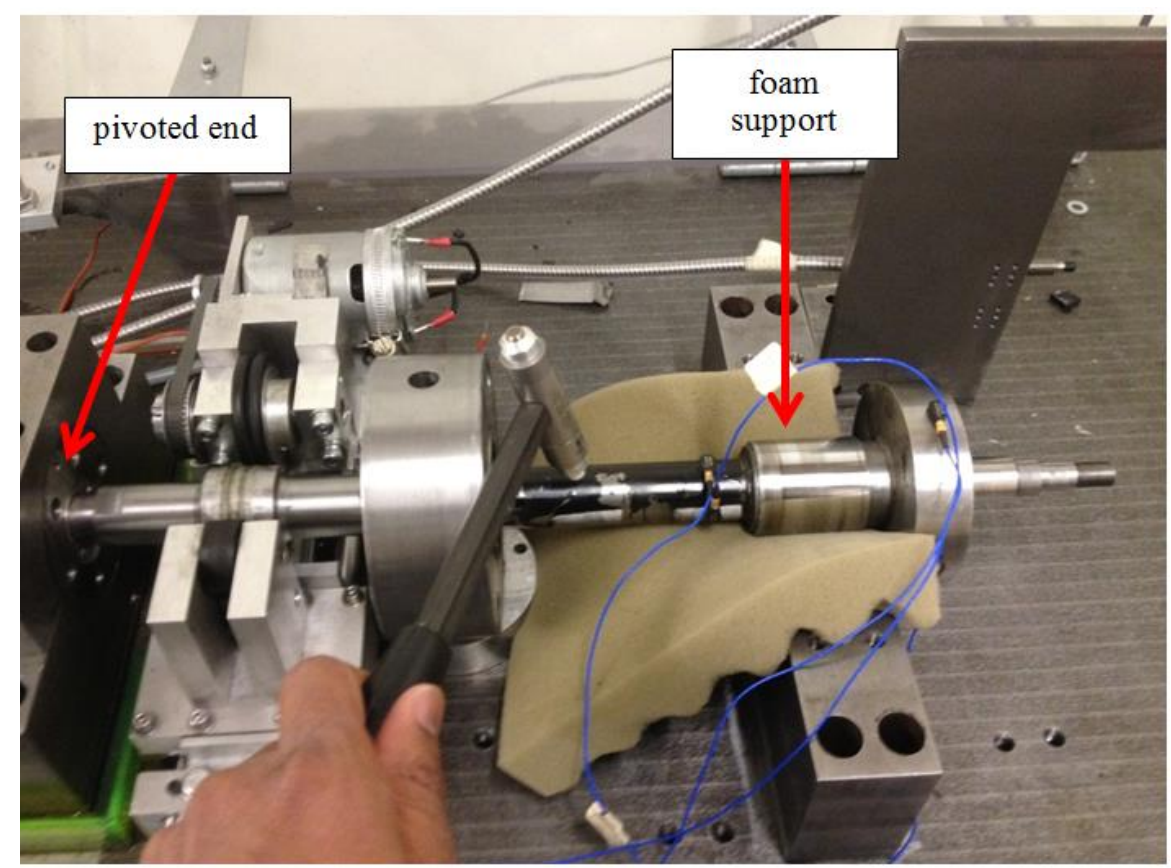

(b)

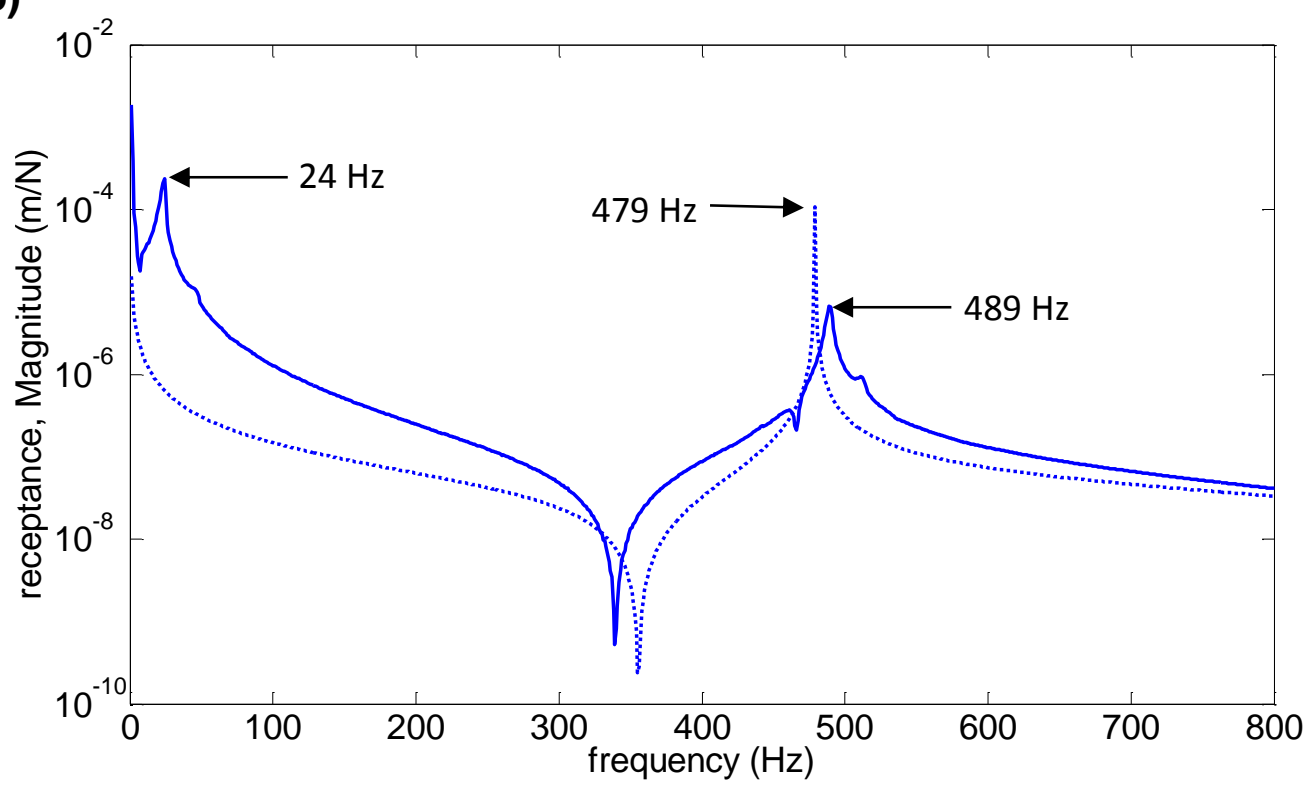

Figure 4. Impact test on linear part: (a) set up; (b) FRFs: measurement (solid line); theoretical (dotted line) 


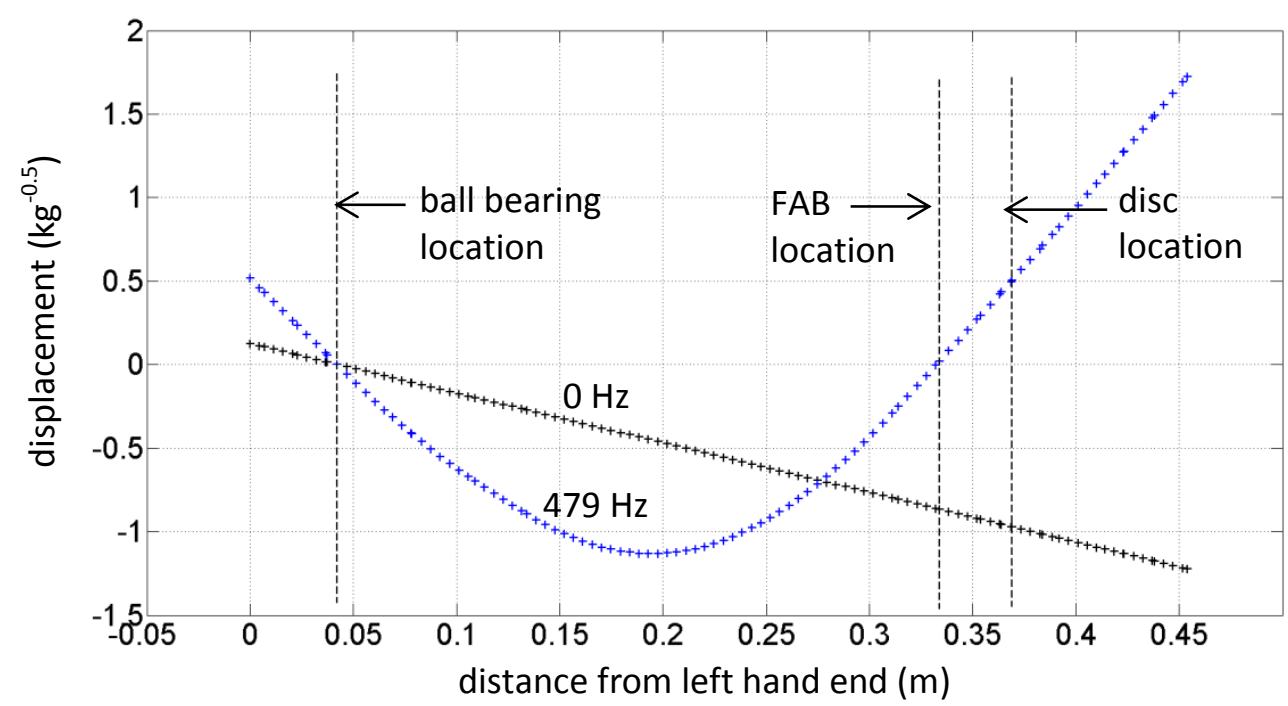

Figure 5. Mass normalised mode shapes of linear part in $x z$ or $y z$ planes.

(a)

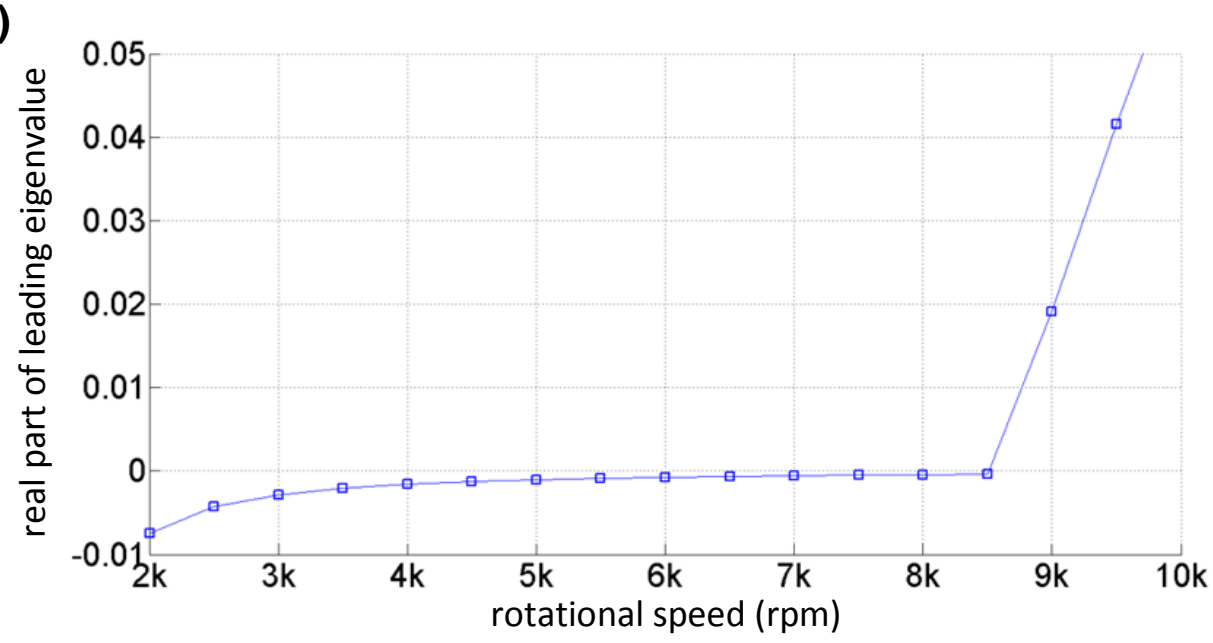

(b)

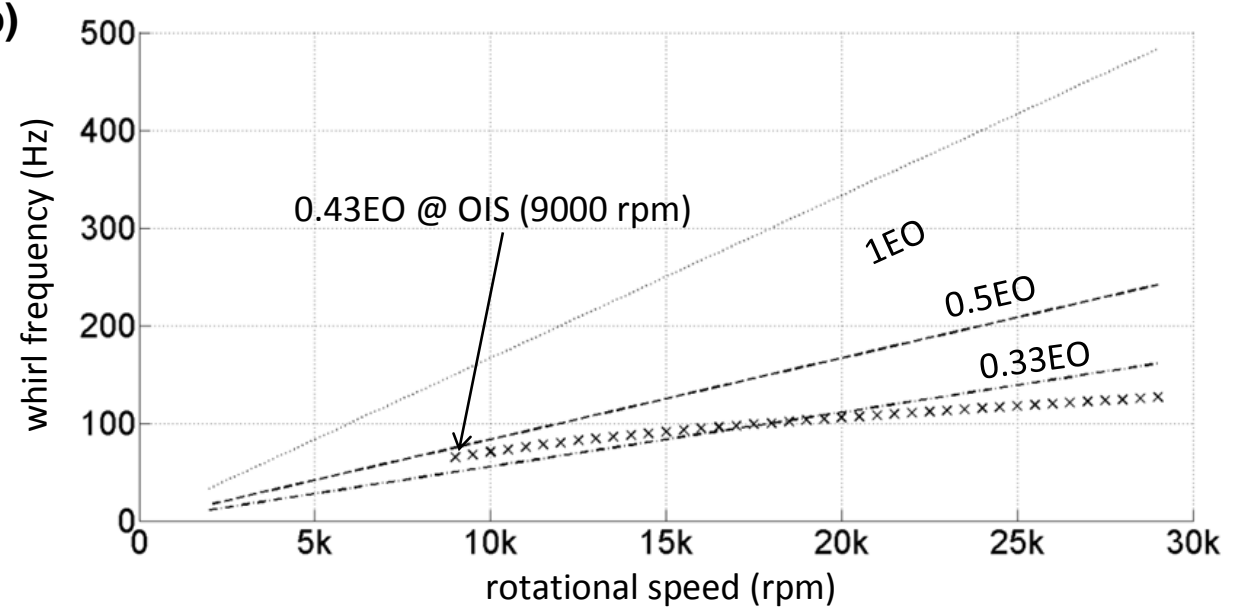

Figure 6. Static equilibrium stability analysis (SESA) results for continuous $\theta$ pad model, non-Gumbel: (a) real part of leading eigenvalue $\lambda_{\mathrm{L}}$; (b) whirl frequency of unstable perturbation (derived from imaginary part of $\lambda_{\mathrm{L}}$ ) 


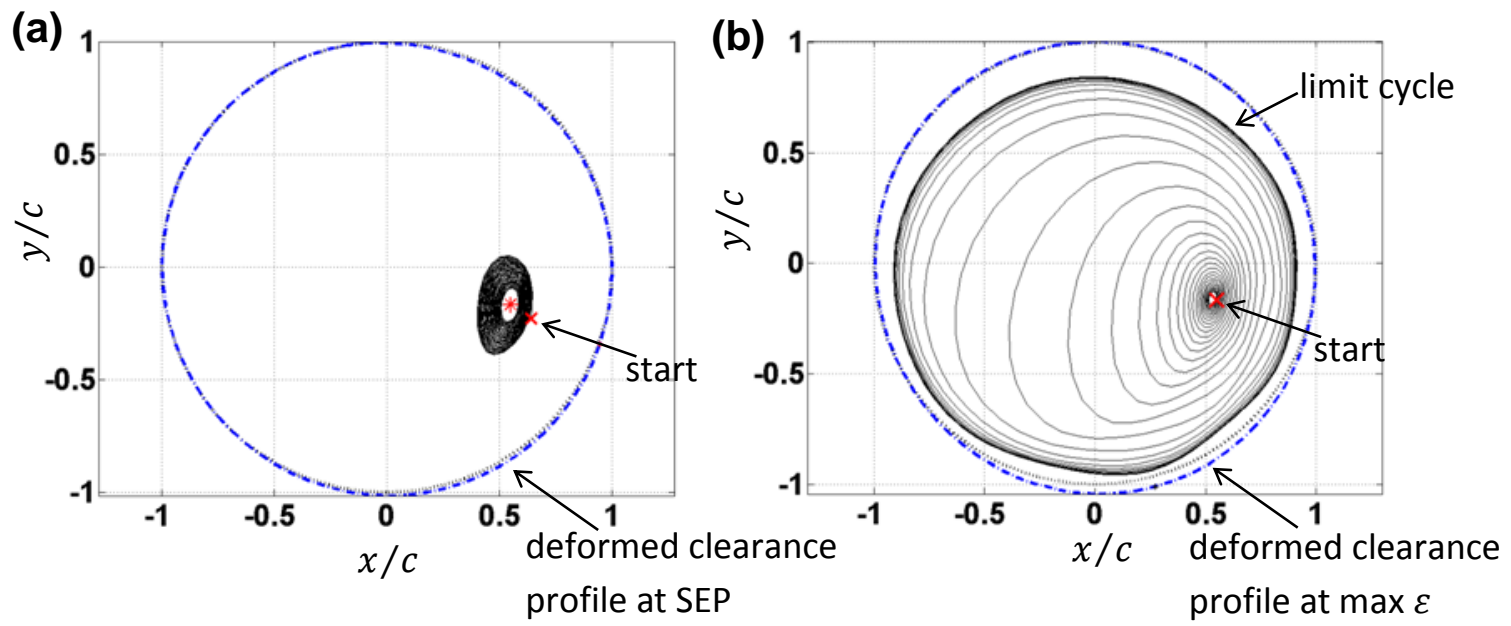

(c)

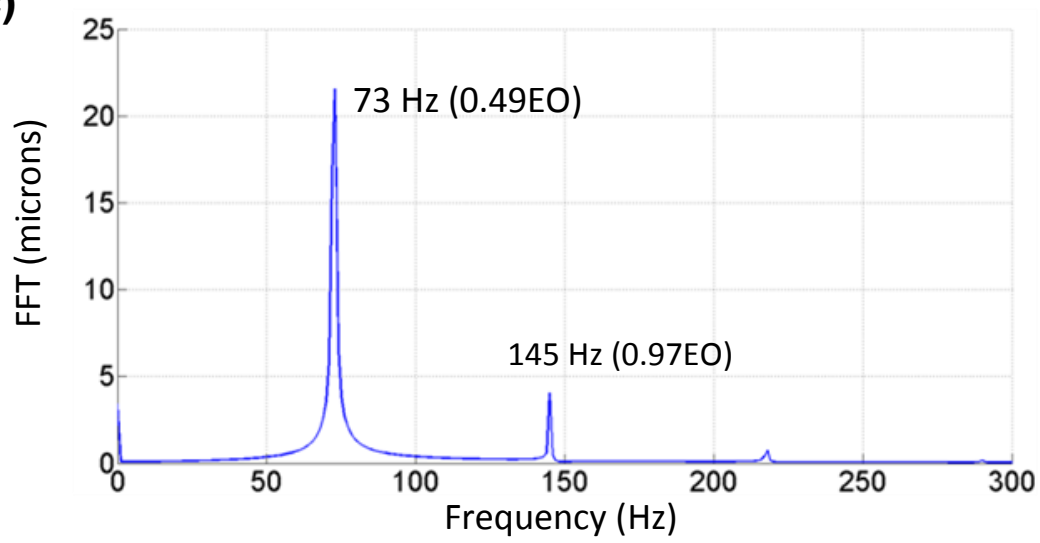

Figure 7. Full nonlinear TNDA results for FAB journal trajectory at zero unbalance (continuous $\theta$ model, non-Gümbel): (a) $8500 \mathrm{rpm}$ (stable) - convergence to static equilibrium position (SEP, shown as red star); (b) $9000 \mathrm{rpm}$ (unstable) - divergence from SEP and convergence to limit cycle; (c) FFT of steady-state limit cycle at $9000 \mathrm{rpm}$ (OSI speed). 


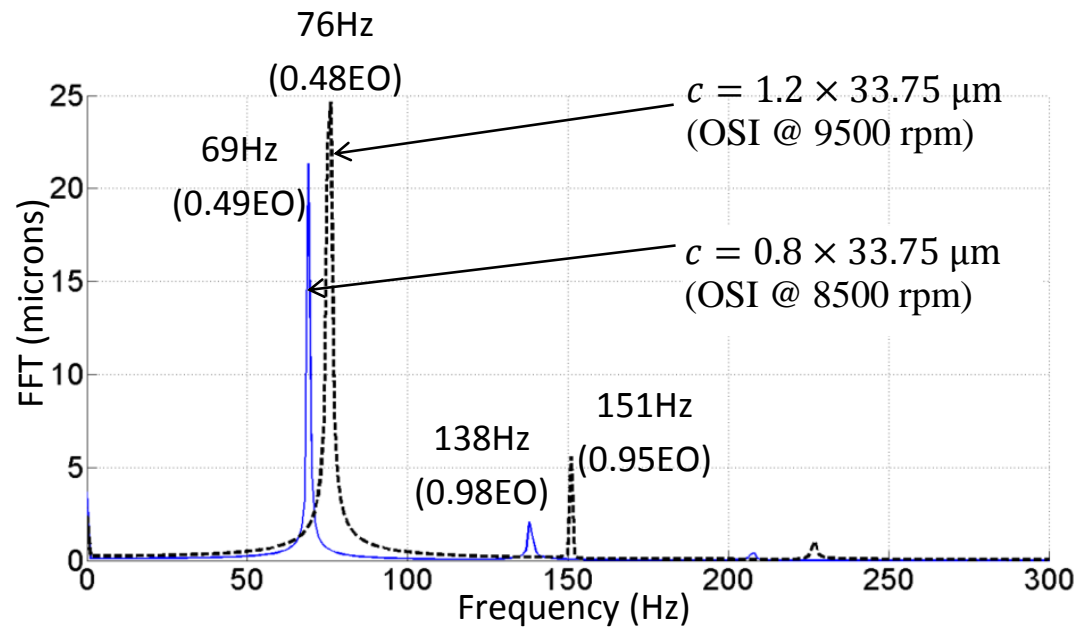

Figure 8. Effect of variability of $\pm 20 \%$ in the nominal clearance: FFT of the steady-state limit cycle (zero unbalance) at the OSI speed (continuous $\theta$ model, non-Gümbel). 
(a)
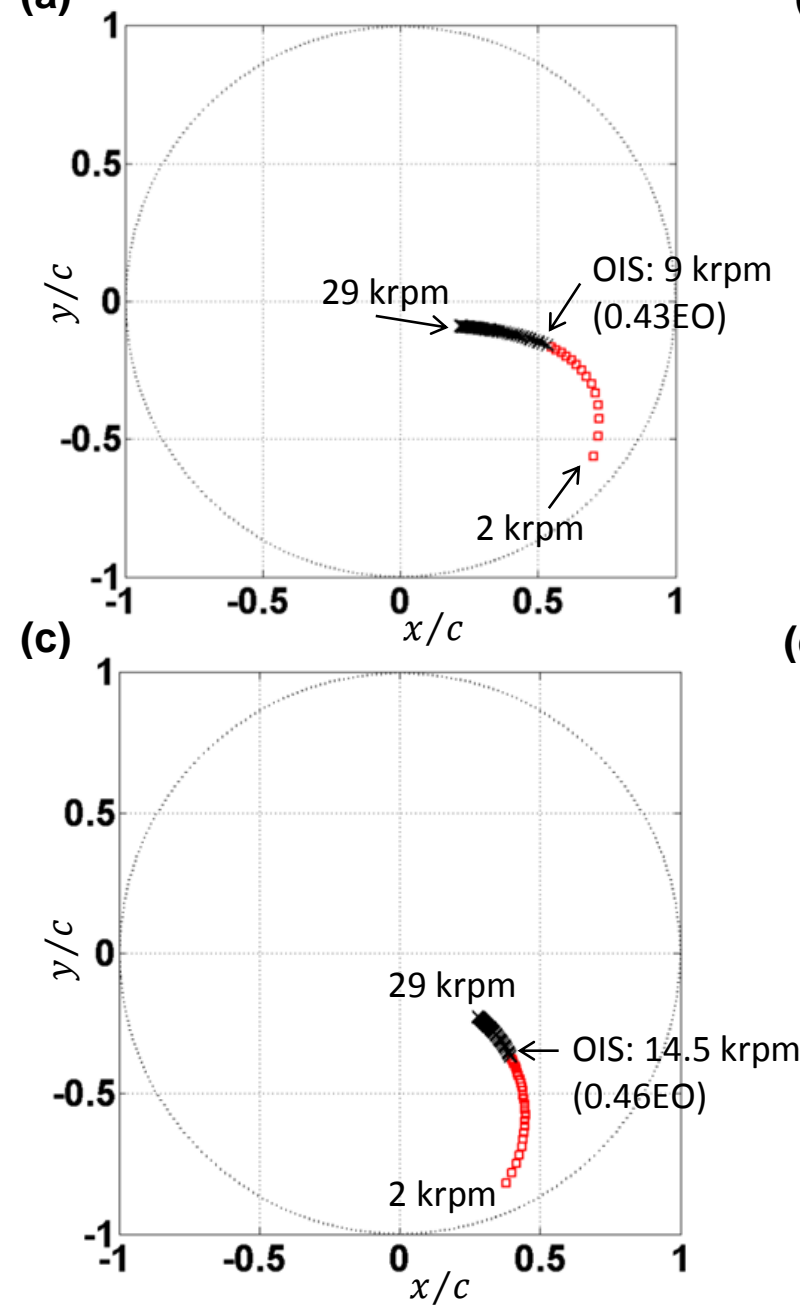

(b)
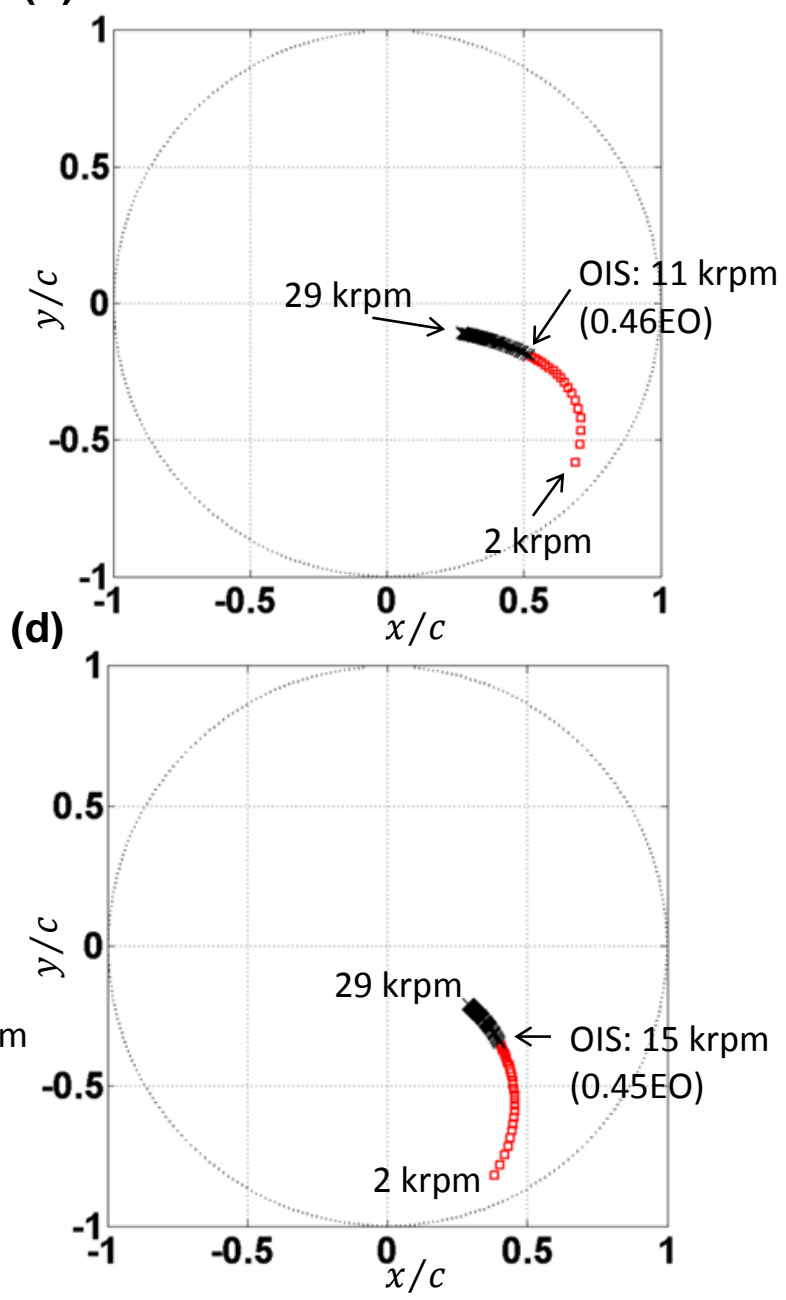

Figure 9. Locus of predicted static equilibrium positions over a range of speeds according to different air film boundary conditions (stable - red squares): (a) continuous $\theta$ pad model, non-Gümbel; (b) finite $\theta$ pad model, non-Gümbel; (c) continuous $\theta$ pad model, Gümbel; (d) finite $\theta$ pad model, Gümbel. 
(a)

(b)

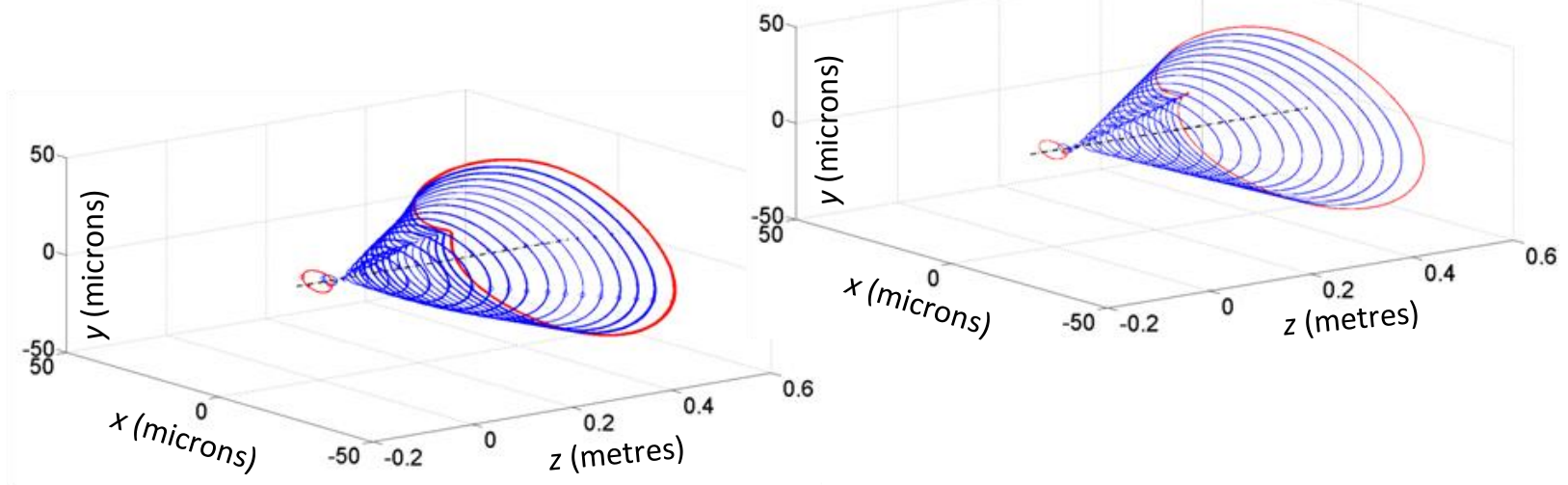

(c)

(d)

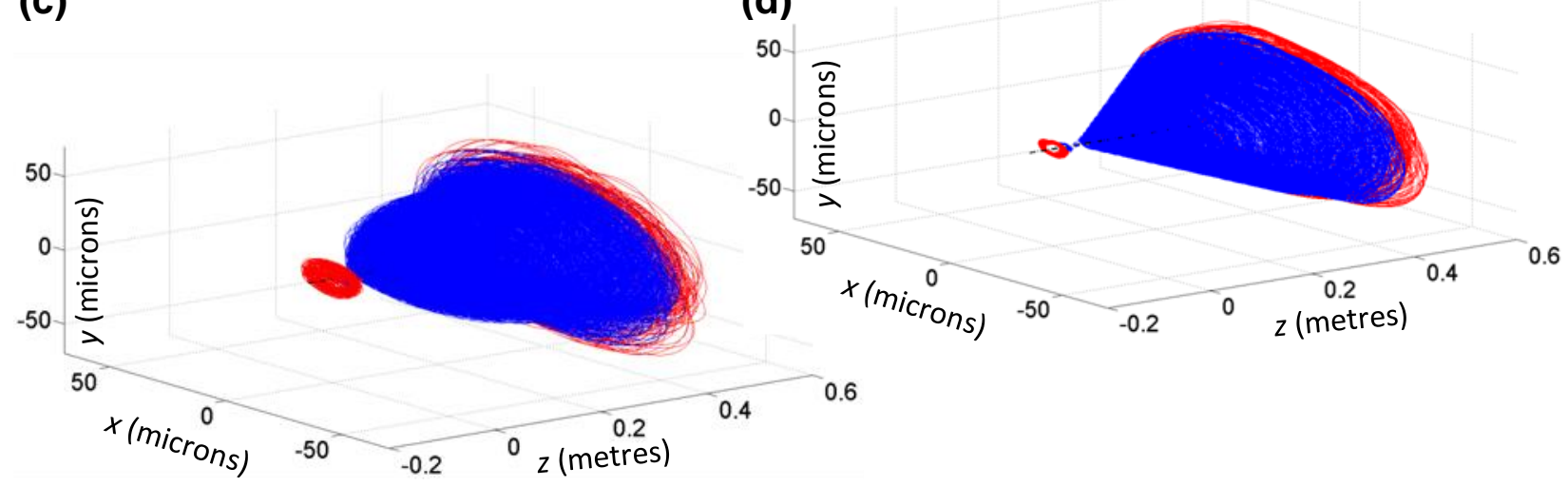

Figure 10. Effect of the number of rotor modes on the predicted operating deflection shape (ODS) (0.5 s of steady-state data, 10 g.mm unbalance, continuous $\theta$ pad model, non-Gümbel): (a) $15 \mathrm{krpm}$ (4 modes); (b) $15 \mathrm{krpm}$ (2 modes); (c) $22 \mathrm{krpm}$ (4 modes); (d) $22 \mathrm{krpm}$ (2 modes). 
(a)

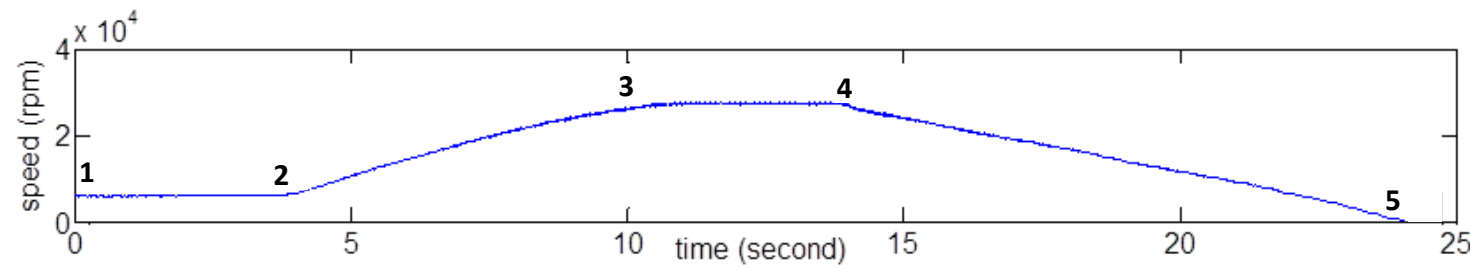

(b)

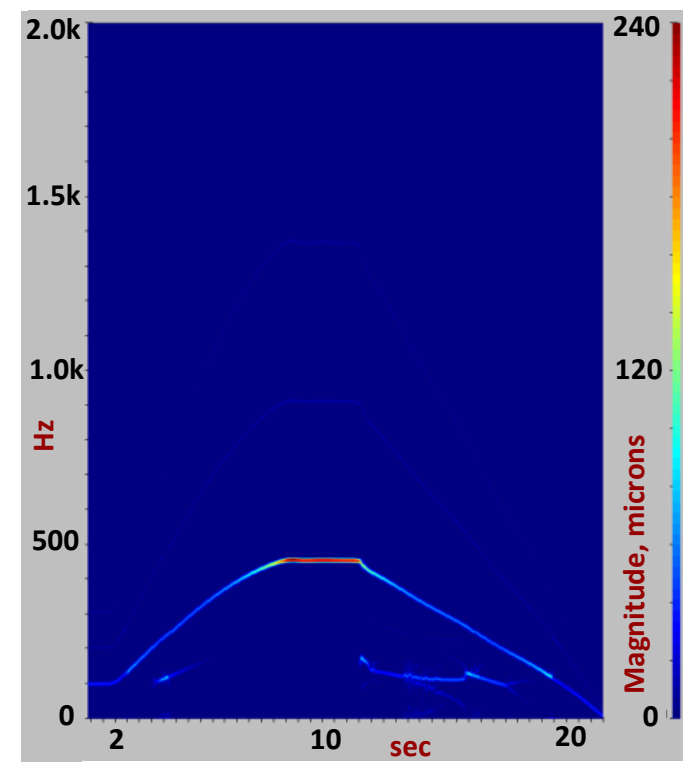

(c)

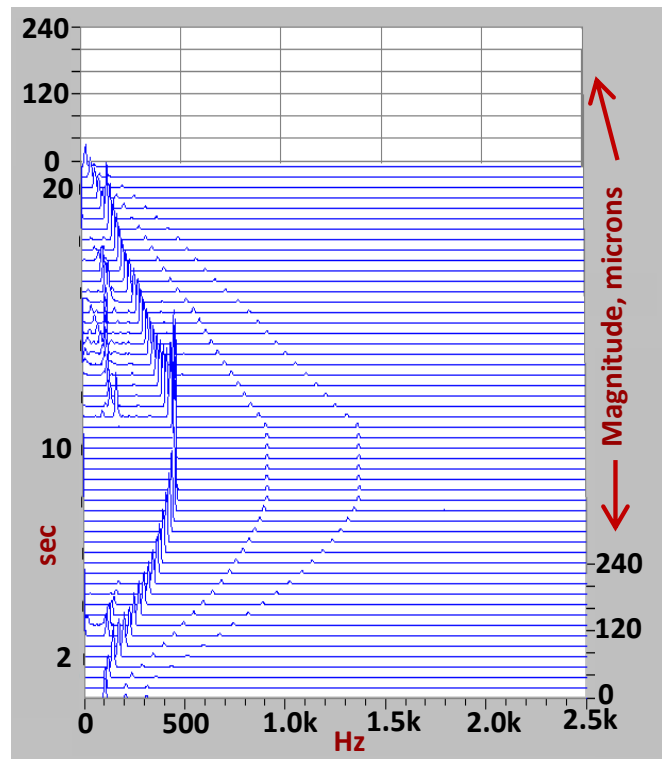

Figure 11. Experimental run for no added unbalance (residual unbalance): (a) rotational speed variation;

(b) spectrogram - frequency-amplitude $v s$ time; (c) spectrogram - amplitude-time $v s$ frequency. 
(a)

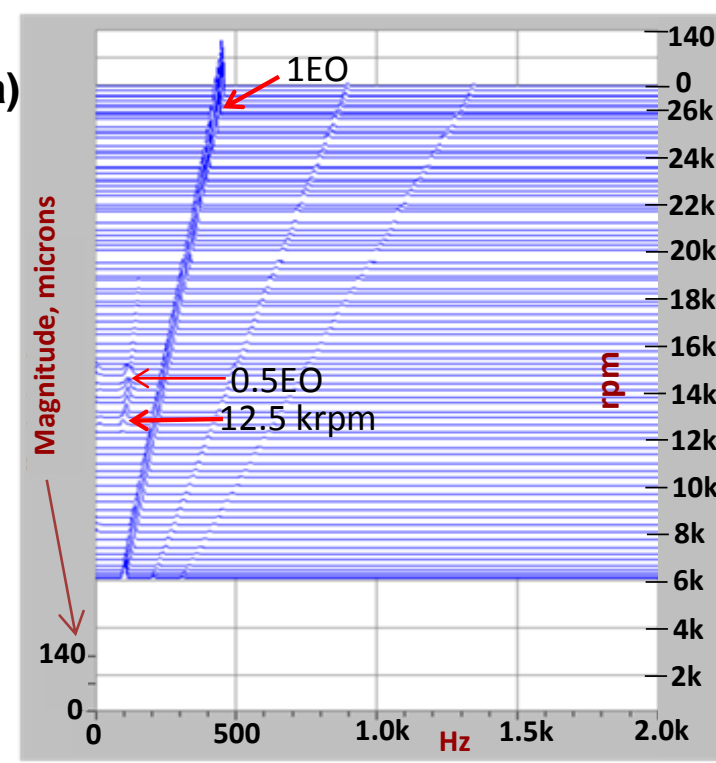

(c)

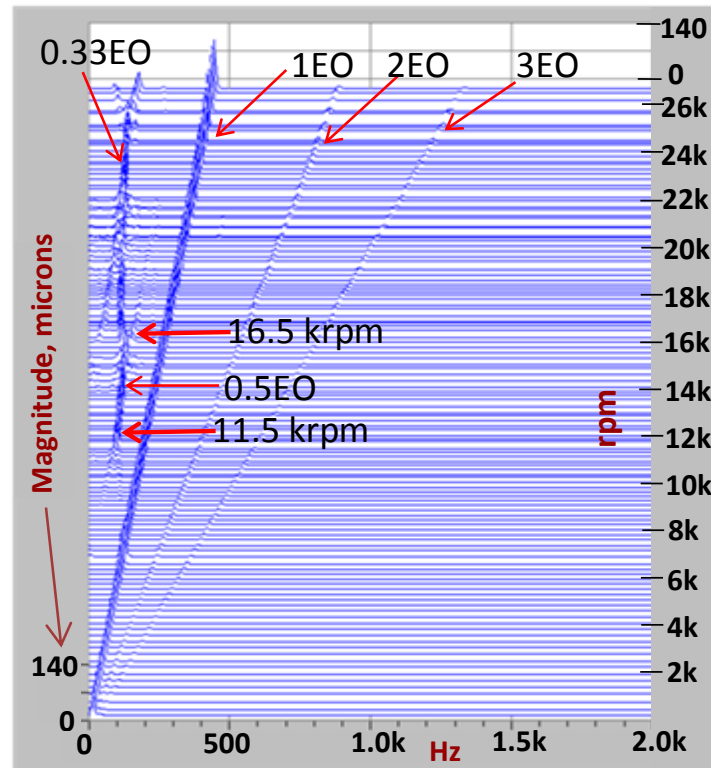

(b)
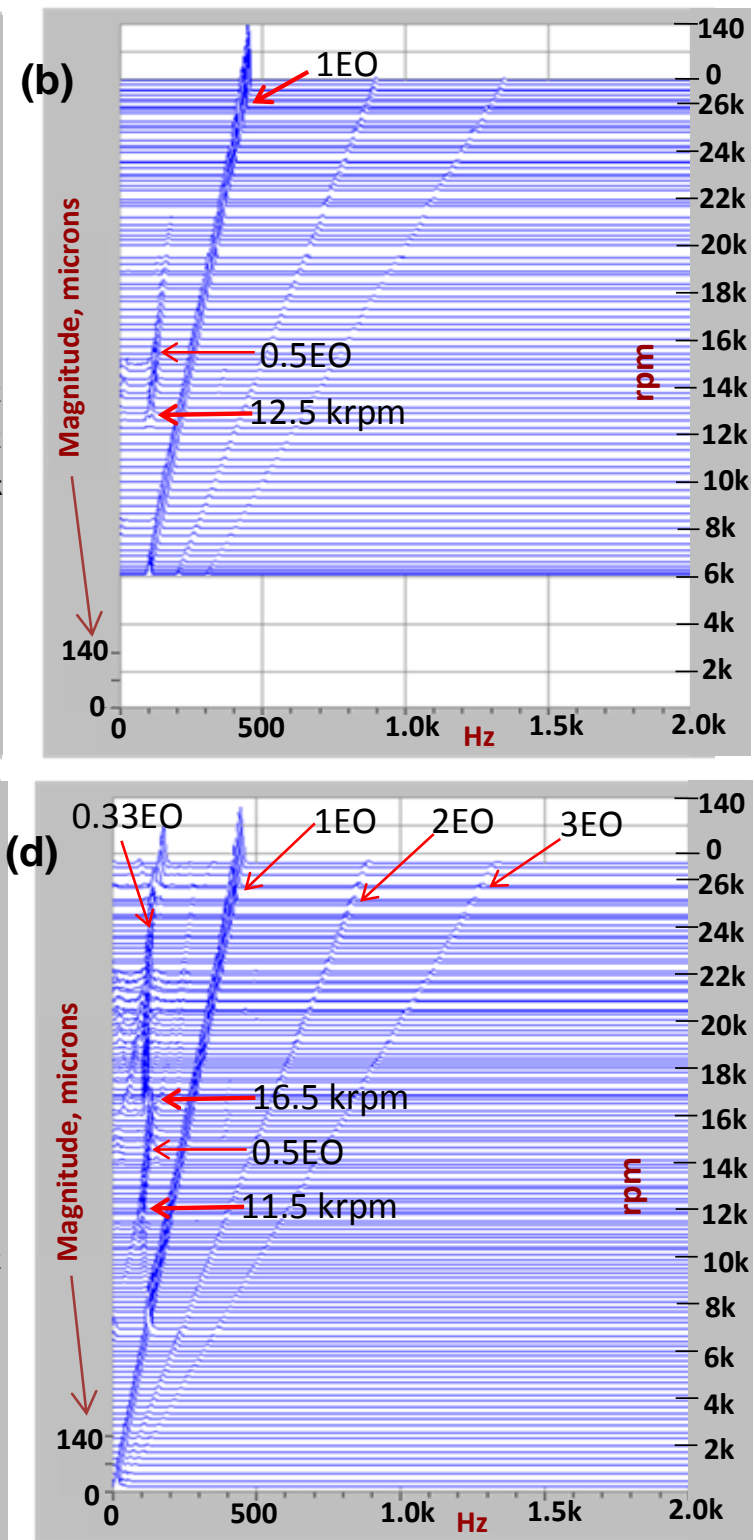

(e)

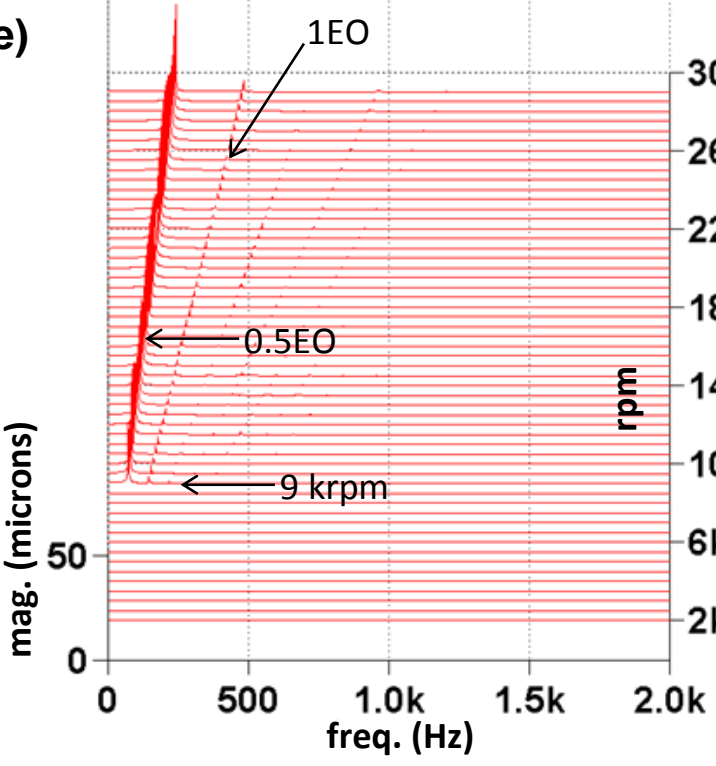

(f)

$30 \mathrm{k}$

$26 \mathrm{k}$

22k

$18 \mathrm{k}$

$14 \mathrm{k}$

$10 \mathrm{k} \frac{\bar{c}}{\delta}$

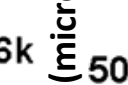

$2 k$ ํำ

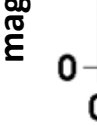

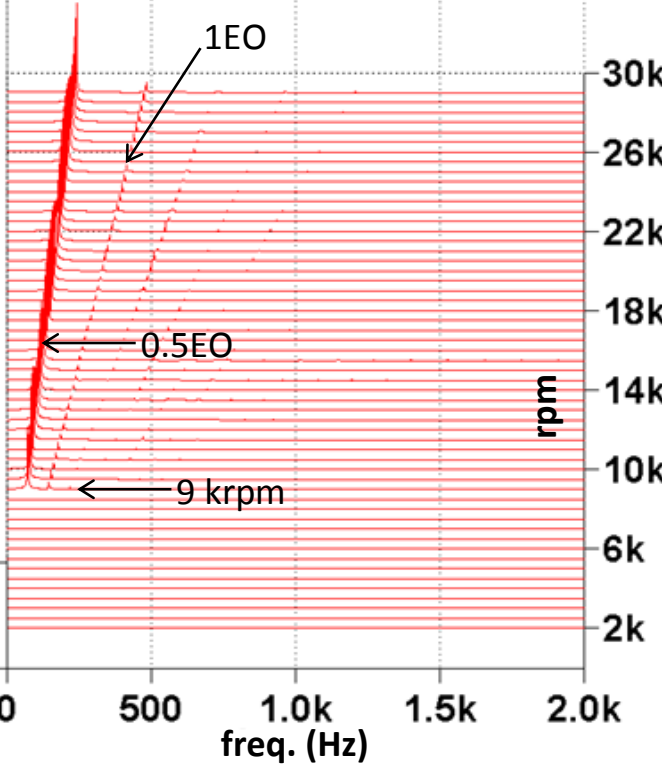

Figure 12. Waterfall diagrams of vibration at disk for no added unbalance: measured run-up $x, y$

((a),(b)); measured coast-down $x, y((\mathrm{c}),(\mathrm{d}))$; theoretical $x, y$ (cont. $\theta$ non-Gümbel) ((e),(f)). 

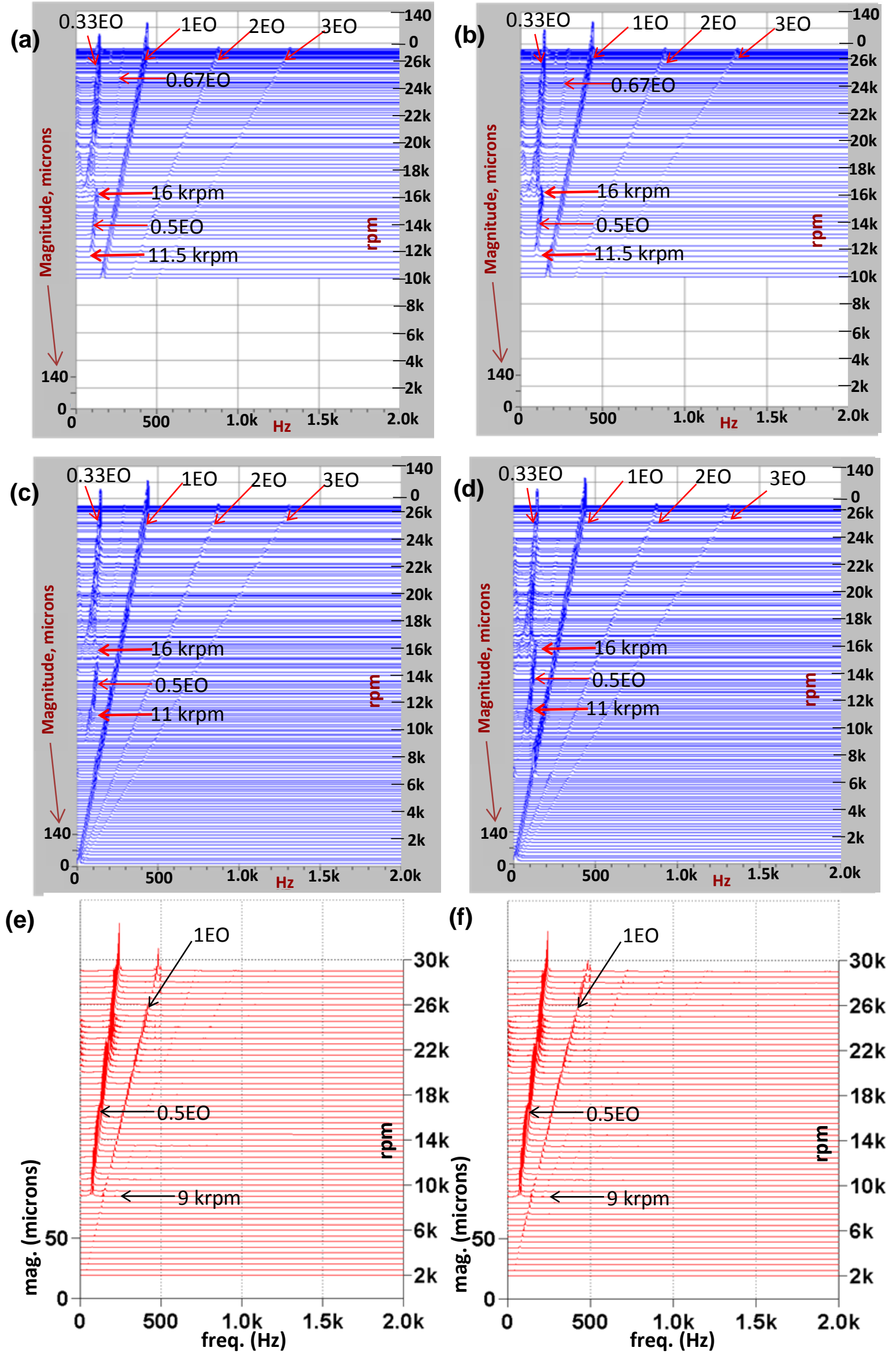

Figure 13. Waterfall diagrams of vibration at disk for $5 \mathrm{~g} . \mathrm{mm}$ added unbalance: measured run-up $x, y$

((a),(b)); measured coast-down $x, y((\mathrm{c}),(\mathrm{d}))$; theoretical $x, y$ (cont. $\theta$ non-Gümbel) ((e),(f)). 


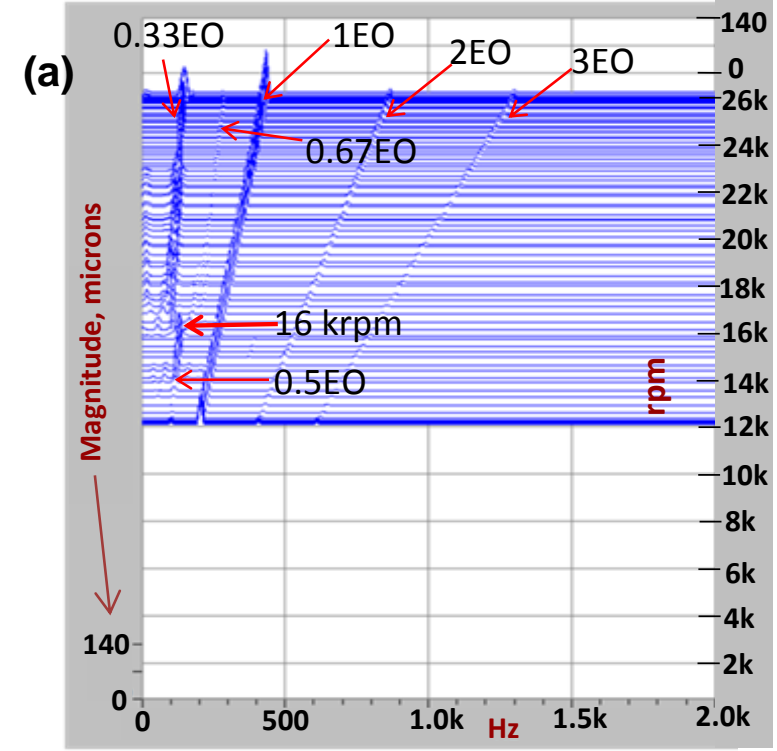

(b)
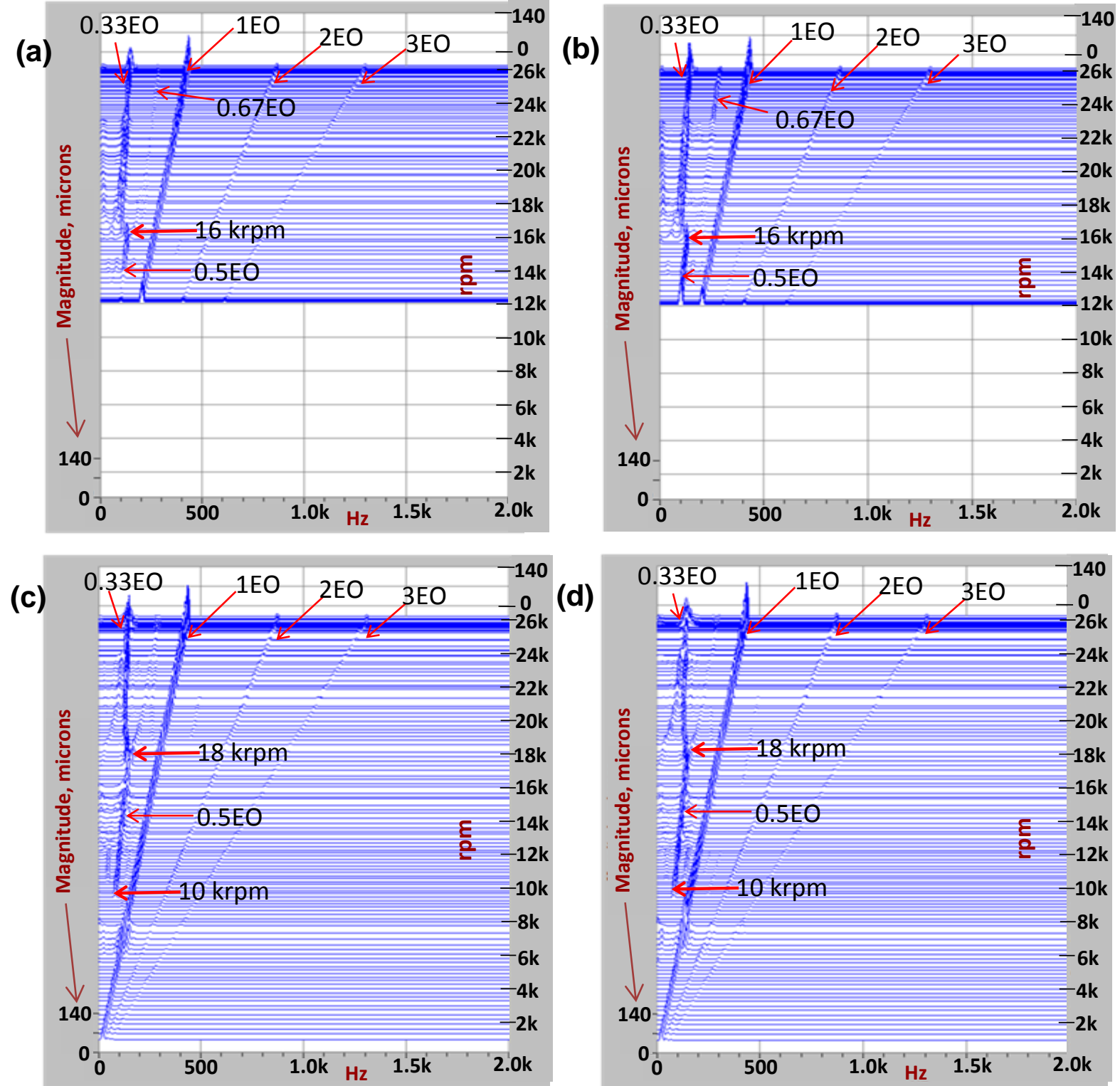

(d)
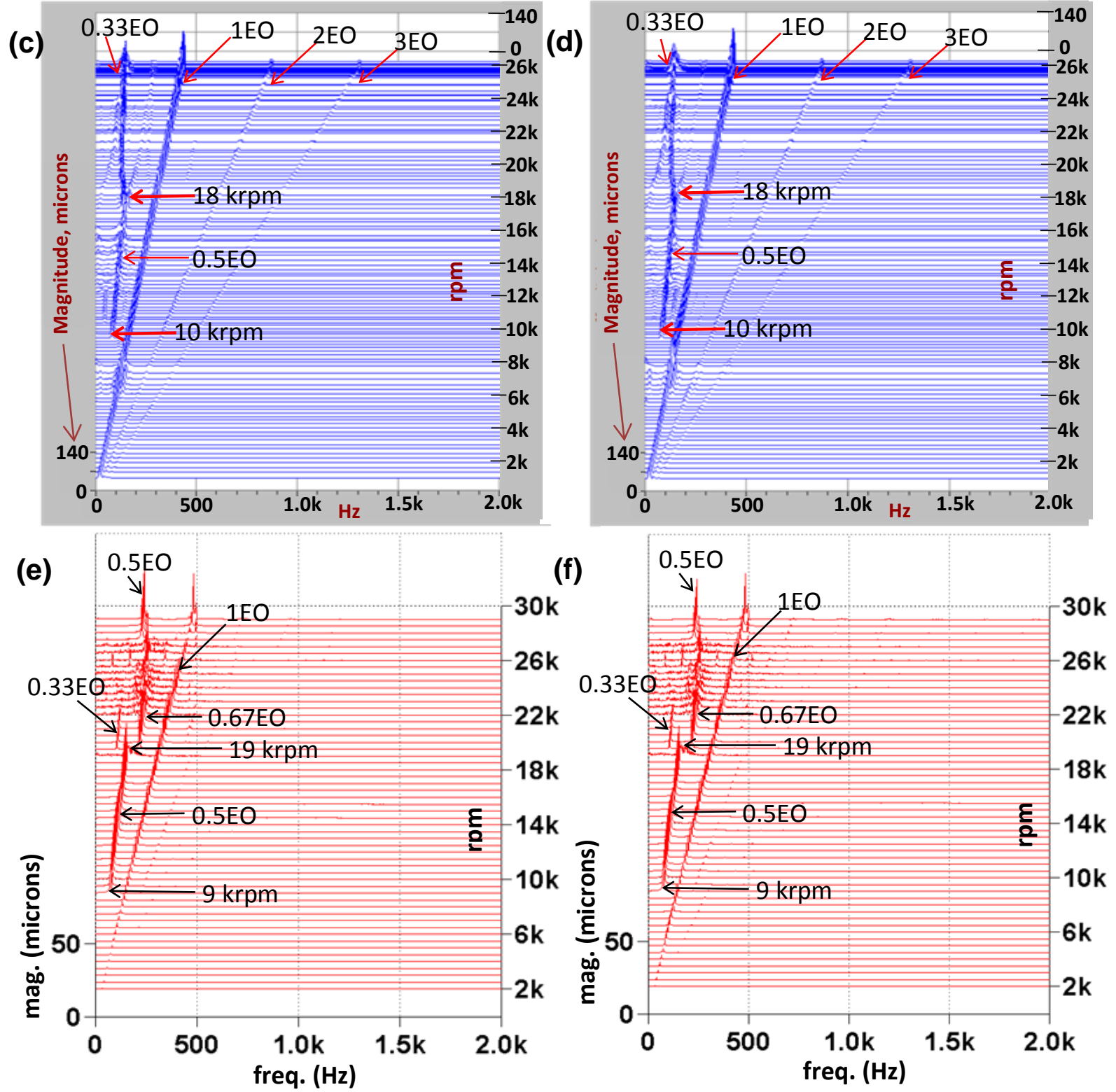

Figure 14. Waterfall diagrams of vibration at disk for 10 g.mm added unbalance: measured run-up $x, y$

((a),(b)); measured coast-down $x, y((\mathrm{c}),(\mathrm{d}))$; theoretical $x, y$ (cont. $\theta$ non-Gümbel) ((e),(f)). 

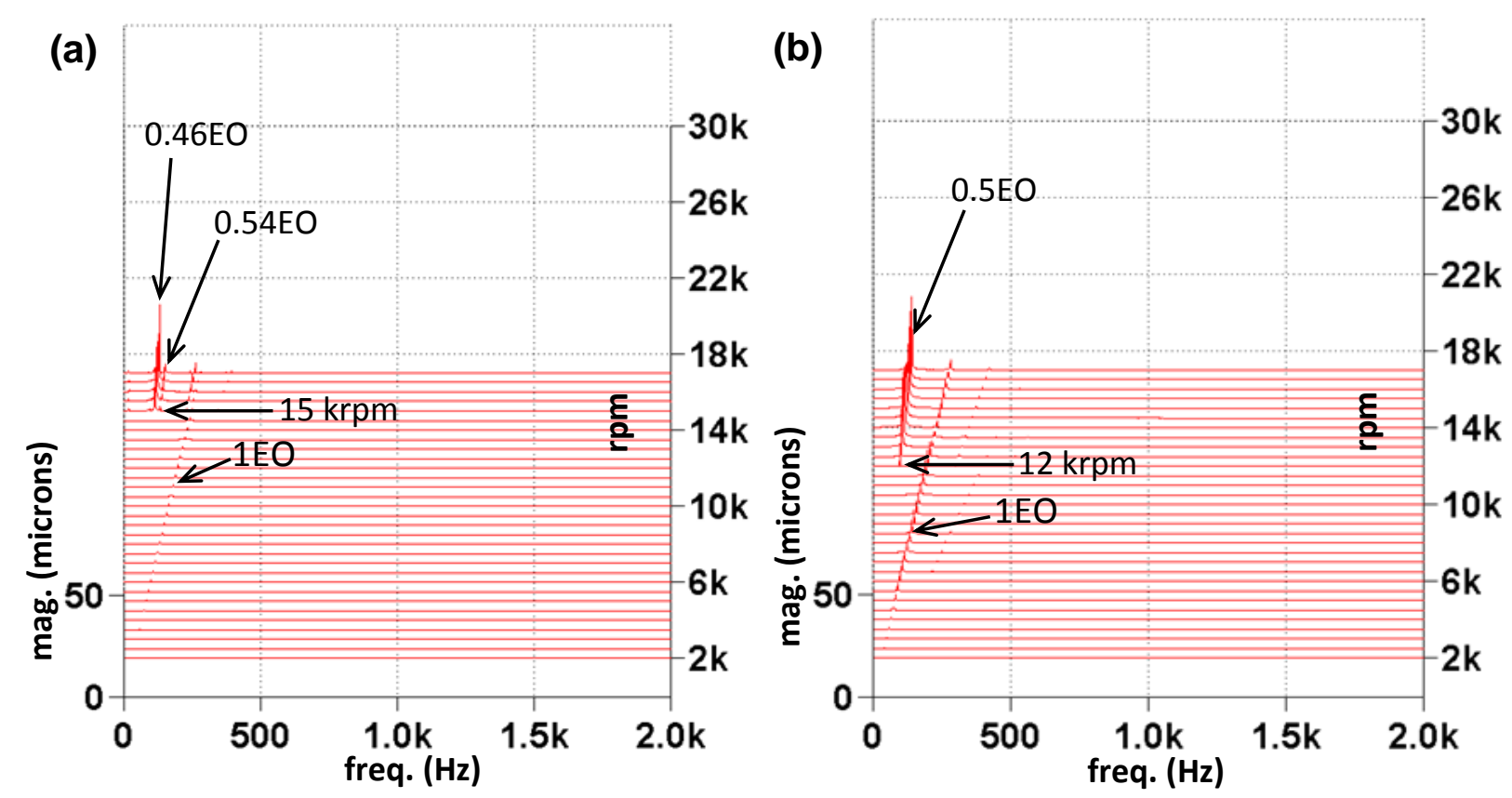

Figure 15: Waterfall diagrams of $y$ vibration at the disk predicted using finite $\theta$ Gümbel conditions for two different levels of added unbalance: (a) 1 g.mm; (b) 5 g.mm. 
(a)

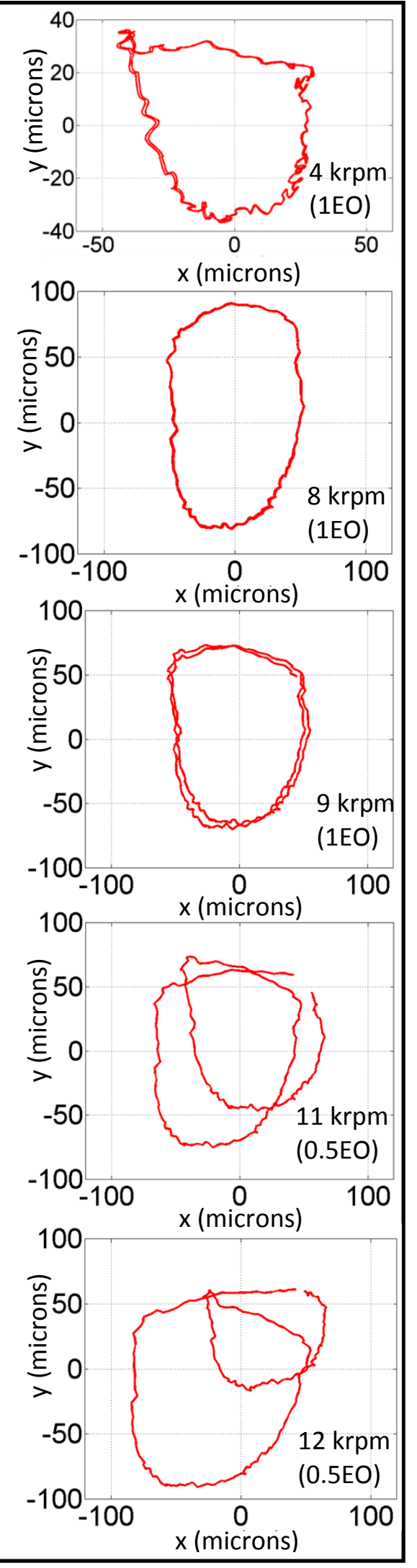

(b)
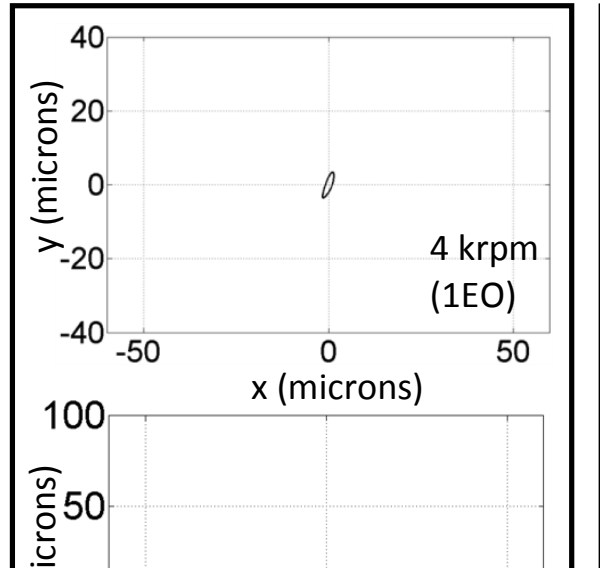

(c)
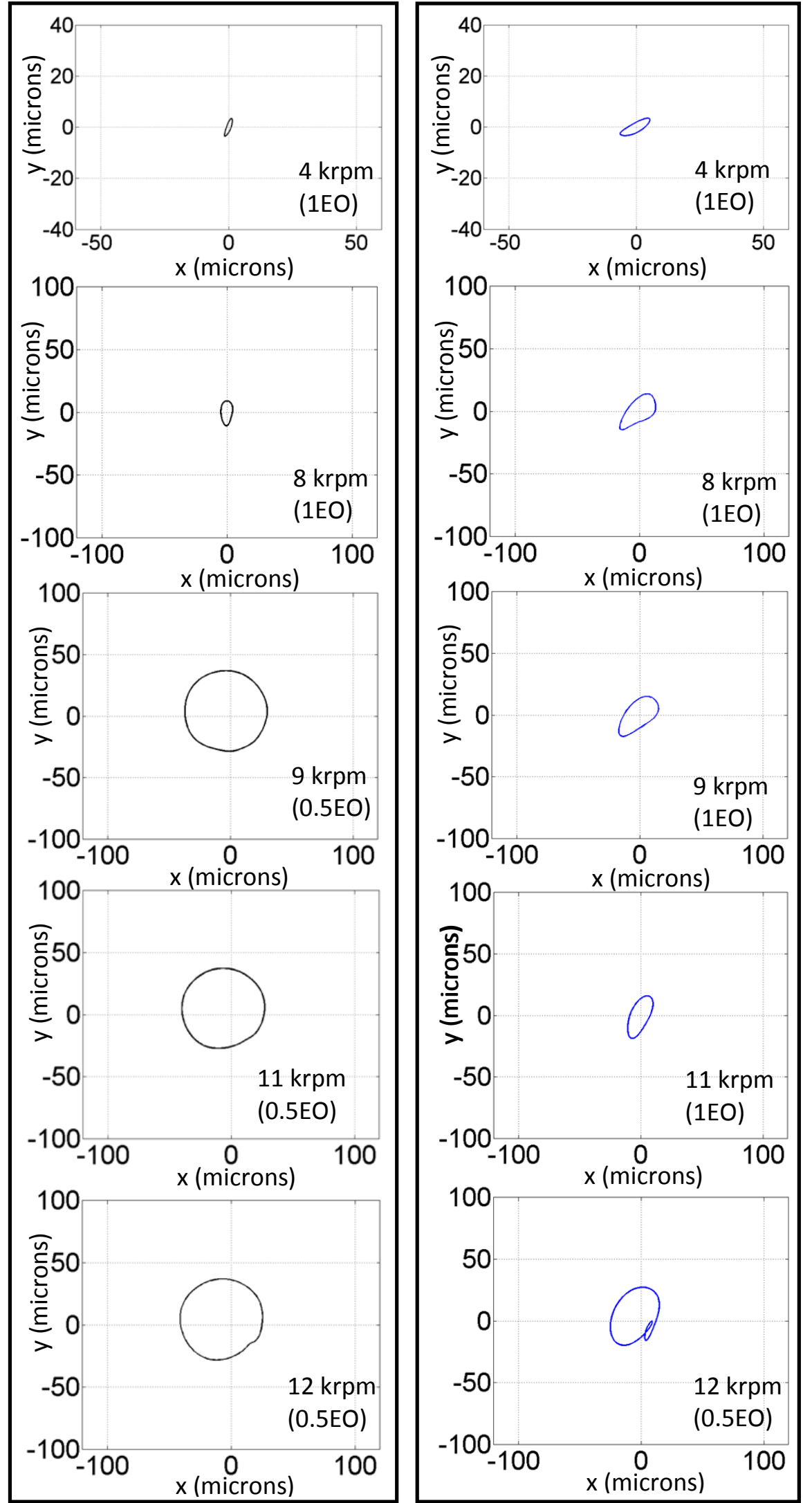

Figure 16. Vibration orbits at disc at 10 g.mm added unbalance at different speeds from $4 \mathrm{krpm}$ to

$12 \mathrm{krpm}$ (lowest significant frequency in spectrum shown in brackets): (a) measured; (b) predicted, cont. $\theta$ non-Gümbel; (c) predicted, finite $\theta$ Gümbel. 
(a)

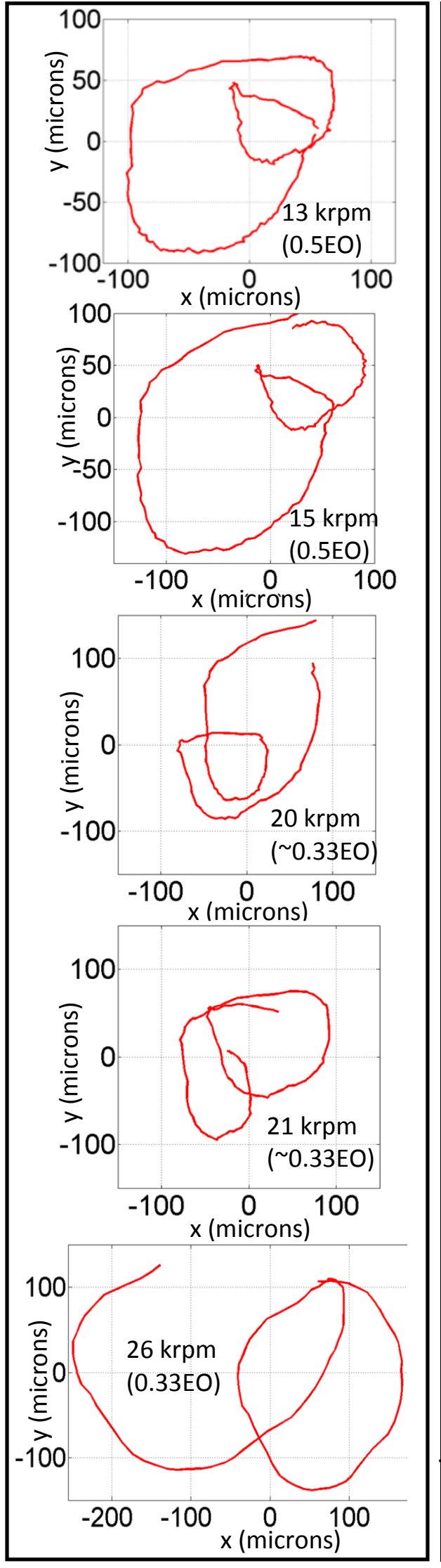

(b)

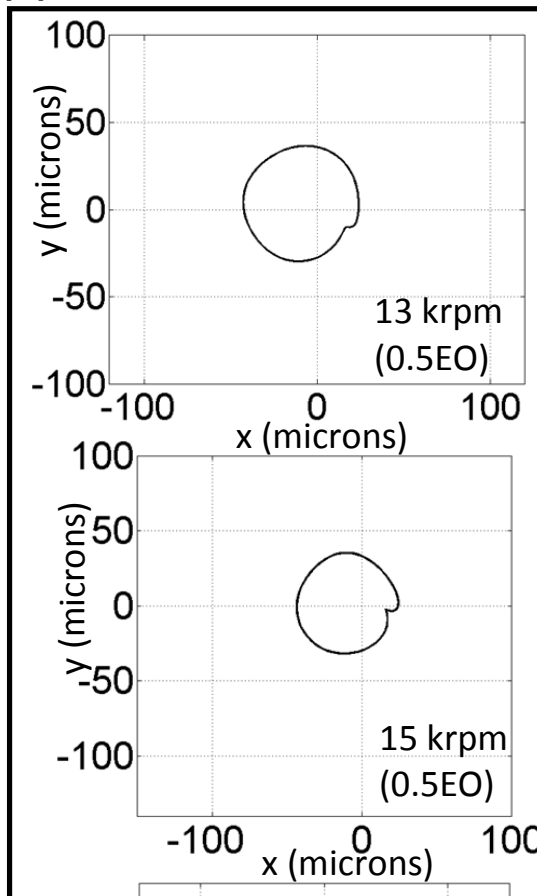

(c)

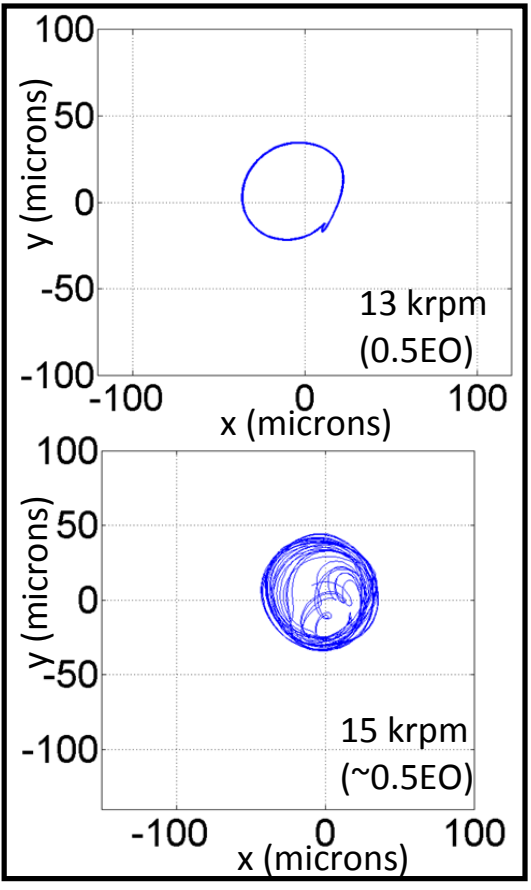

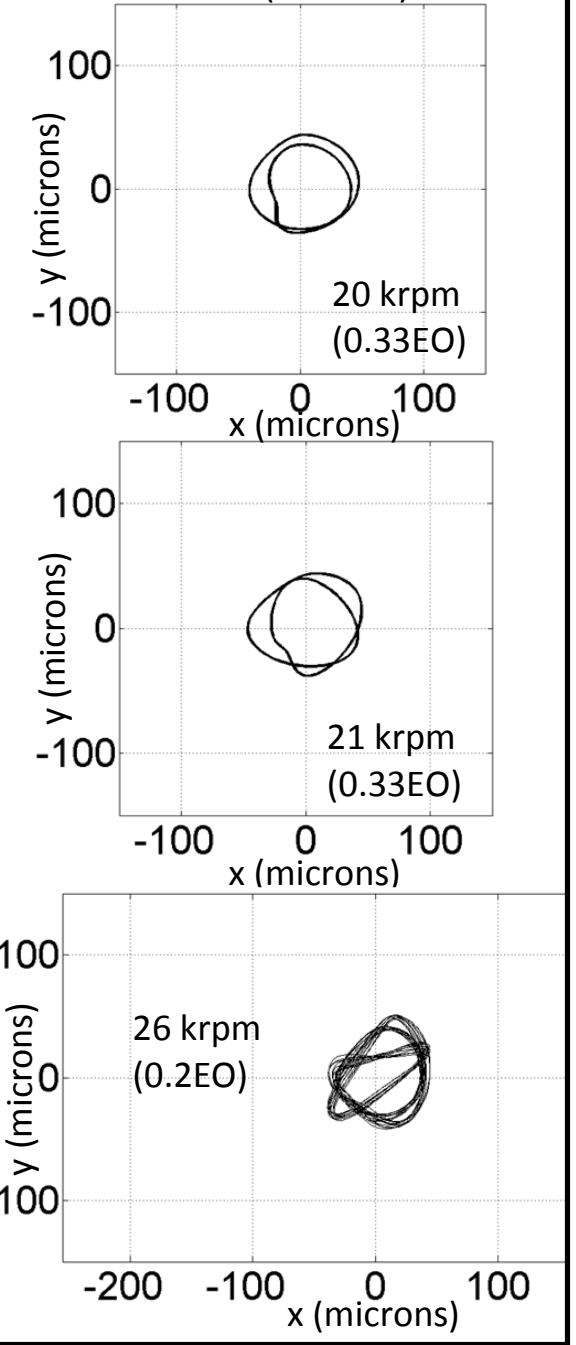

Figure 17. Vibration orbits at disc at $10 \mathrm{~g} . \mathrm{mm}$ added unbalance at different speeds from $13 \mathrm{krpm}$ to $26 \mathrm{krpm}$ (lowest significant frequency in spectrum shown in brackets): (a) measured; (b) predicted, cont. $\theta$ non-Gümbel; (c) predicted, finite $\theta$ Gümbel. 


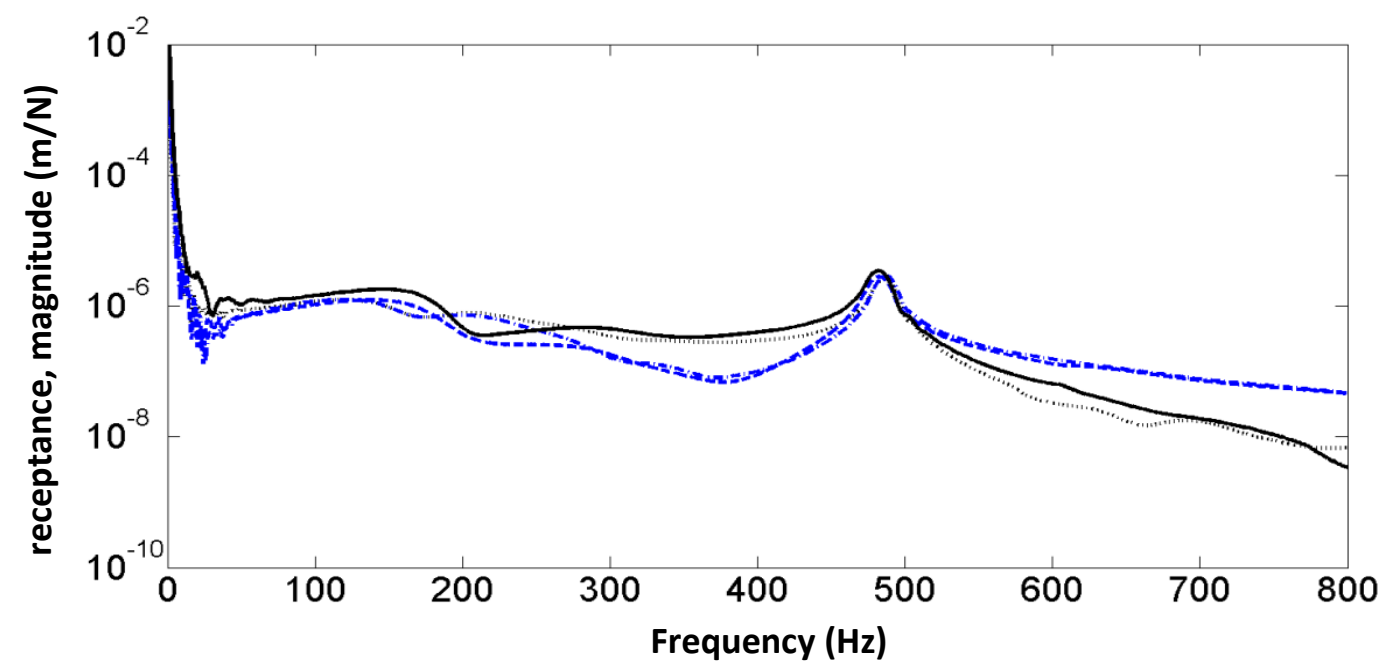

Figure 18. Two different receptance FRFs relating different points on the rig fitted alternatively with old and new FABs: FRF no.1 with old bearing (solid black line); FRF no. 1 with new bearing (dotted blackline); FRF no.2 with old bearing (dashed blue line); FRF no. 2 with new bearing (dash-dot blue line).

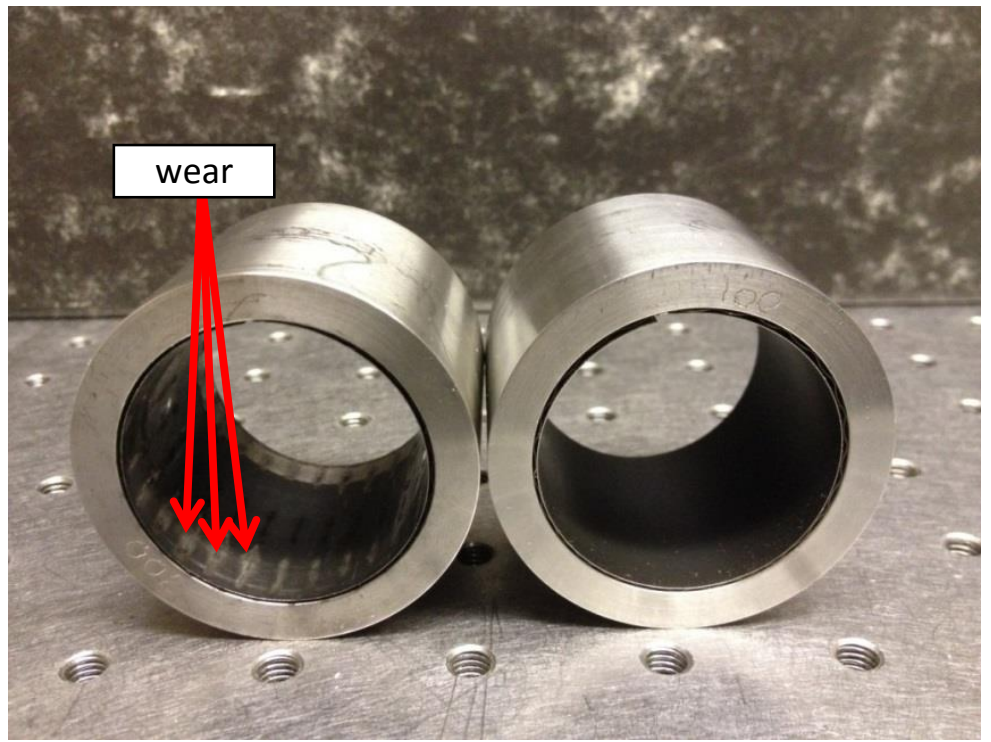

Figure 19. Condition of tested bearing compared with identical new bearing. 


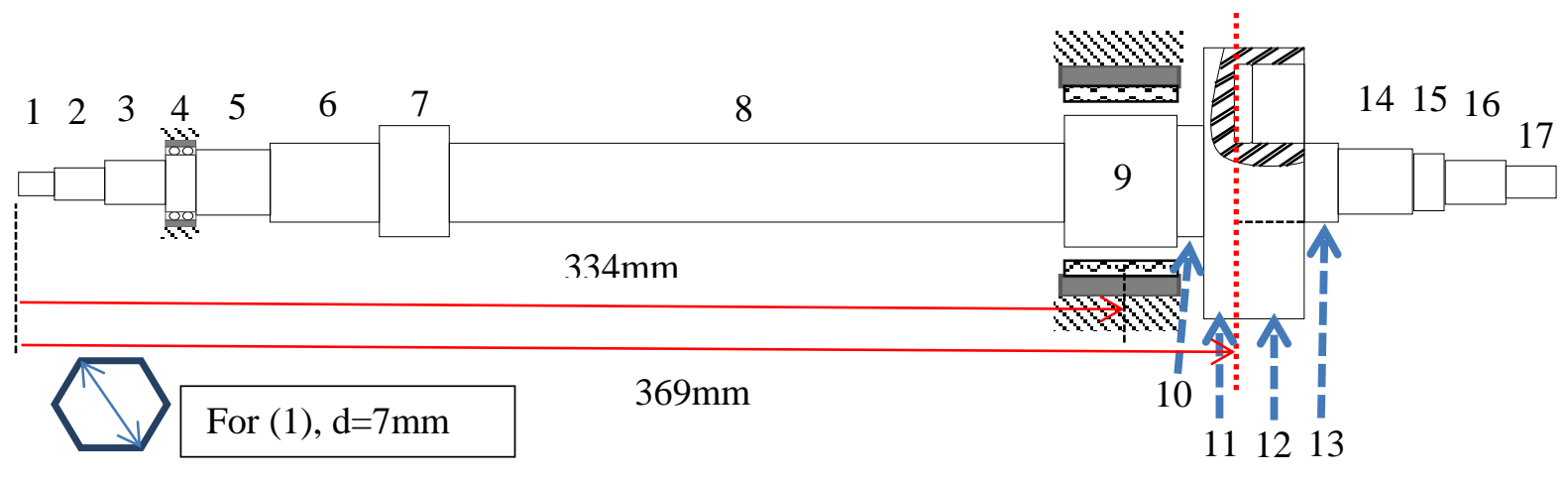

\begin{tabular}{|l|l|l|}
\hline $1-$ hexagonal: $\mathrm{d}=7 \mathrm{~mm}, \mathrm{l}=7 \mathrm{~mm}$ & $7-$ round: $\mathrm{d}=34 \mathrm{~mm}, \mathrm{l}=25 \mathrm{~mm}$ & $13-$ round: $\mathrm{d}=24 \mathrm{~mm}, \mathrm{l}=23 \mathrm{~mm}$ \\
\hline $2-$ round: $\mathrm{d}=10 \mathrm{~mm}, \mathrm{l}=16 \mathrm{~mm}$ & $8-$ round: $\mathrm{d}=24 \mathrm{~mm}, \mathrm{l}=180 \mathrm{~mm}$ & $14-$ round: $\mathrm{d}=18 \mathrm{~mm}, \mathrm{l}=22 \mathrm{~mm}$ \\
\hline $3-$ round: $\mathrm{d}=12 \mathrm{~mm}, \mathrm{l}=14.5 \mathrm{~mm}$ & $9-$ round: $\mathrm{d}=38.1 \mathrm{~mm}, \mathrm{l}=40 \mathrm{~mm}$ & $15-$ round: $\mathrm{d}=15 \mathrm{~mm}, \mathrm{l}=9.5 \mathrm{~mm}$ \\
\hline $4-$ round: $\mathrm{d}=15 \mathrm{~mm}, \mathrm{l}=9.5 \mathrm{~mm}$ & $10-$ round: $\mathrm{d}=34 \mathrm{~mm}, \mathrm{l}=10 \mathrm{~mm}$ & $16-$ round: $\mathrm{d}=12 \mathrm{~mm}, \mathrm{l}=14.5 \mathrm{~mm}$ \\
\hline $5-$ round: $\mathrm{d}=18 \mathrm{~mm}, \mathrm{l}=22 \mathrm{~mm}$ & $11-$ round: $\mathrm{d}=80 \mathrm{~mm}, \mathrm{l}=5 \mathrm{~mm}$ & $17-$ round: $\mathrm{d}=10 \mathrm{~mm}, \mathrm{l}=16 \mathrm{~mm}$ \\
\hline $6-$ round: $\mathrm{d}=24 \mathrm{~mm}, \mathrm{l}=40 \mathrm{~mm}$ & $12-$ hollow round bar: $\mathrm{d}($ outer $)=80 \mathrm{~mm}, \mathrm{~d}($ inner $)=74 \mathrm{~mm}, \mathrm{l}=15 \mathrm{~mm}$ \\
\hline \multicolumn{2}{|c|}{ Note: $\mathrm{d}=$ diameter, $\mathrm{l}=$ length; segments $(12)$ and $(13)$ start at the same point $(------)$} \\
\hline \multicolumn{2}{|c|}{ Young's Modulus $200 \mathrm{GN} / \mathrm{m}^{2}$, density $7860 \mathrm{~kg} / \mathrm{m}^{3}}$, \\
\hline
\end{tabular}

Figure A1. Geometric and physical parameters of rotor. 